\title{
Endoscopic endonasal surgery of the midline skull base: anatomical study and clinical considerations
}

\author{
Luigi M. Cavallo, M.D., Ph.D., Andrea Messina, M.D., Paolo Cappabianca, M.D., \\ Felice Esposito, M.D., Enrico de Divitiis, M.D., Paul Gardner, M.D., \\ AND MANFRed TschabitsCher, M.D.
}

\author{
Department of Neurological Sciences, Division of Neurosurgery, Università degli Studi di Napoli \\ Federico II, Naples, Italy; Microsurgical and Endoscopic Anatomy Study Group, University of \\ Vienna, Austria; and Department of Neurosurgery, University of Pittsburgh Medical Center, \\ Pittsburgh, Pennsylvania
}

\begin{abstract}
Object. The midline skull base is an anatomical area that extends from the anterior limit of the cranial fossa down to the anterior border of the foramen magnum. Resection of lesions involving this area requires a variety of innovative skull base approaches. These include anterior, anterolateral, and posterolateral routes, performed either alone or in combination, and resection via these routes often requires extensive neurovascular manipulation. The goals in this study were to define the application of the endoscopic endonasal approach and to become more familiar with the views and skills associated with the technique by using cadaveric specimens.

Methods. To assess the feasibility of the endonasal route for the surgical management of lesions in the midline skull base, five fresh cadaver heads injected with colored latex were dissected using a modified endoscopic endonasal approach.

Full access to the skull base and the cisternal space around it is possible with this route. From the crista galli to the spinomedullary junction, with incision of the dura mater, a complete visualization of the carotid and vertebrobasilar arterial systems and of all 12 of the cranial nerves is obtainable.

Conclusions. The major potential advantage of the endoscopic endonasal approach to the skull base is that it provides a direct anatomical route to the lesion without traversing any major neurovascular structures, obviating brain retraction. Many tumors grow in a medial-to-lateral direction, displacing structures laterally as they expand, creating natural corridors for their resection via an anteromedial approach.

Potential disadvantages of this procedure include the relatively restricted working space and the danger of an inadequate dural repair with cerebrospinal fluid (CSF) leakage and potential for meningitis resulting. These approaches often require a large opening of the dura mater over the tuberculum sellae and posterior planum sphenoidale, or retroclival space. In addition, they typically involve large intraoperative CSF leaks, which necessitate precise and effective dural closure.
\end{abstract}

KEY Words • endoscopy • skull base • endonasal approach • anatomical study

The transsphenoidal midline route has been the standard approach for the surgical treatment of most intrasellar tumors for more than three decades., ${ }^{5,451}$ This is due to the versatility of the transsphenoidal approach for a variety of lesions in the sellar area and is based on solid foundations: it is the least traumatic route to the sella turcica, it avoids brain retraction, it provides excellent visualization of the pituitary gland and lesions related to that structure. As a result of these advantages it offers a lower morbidity and mortality rate when compared with transcranial procedures, and this also naturally leads to a shorter hospital stay. Nevertheless, a variety of innovative skull base approaches (including anterior, anterolateral, and posterolateral routes, which often require extensive neurovascular manipulation to gain

Abbreviation used in this paper: $\mathrm{BA}=$ basilar artery; $\mathrm{CSF}=$ cerebrospinal fluid; ICA = internal carotid artery; VA = vertebral artery. access to the lesion) have been developed to allow resection of extraaxial lesions of the anterior skull base or lesions ventral to the brainstem ${ }^{3,7,8,15,18,20-24,26-28,36,41,43,49,52,53,56,59-62,64}$ that are outside of the sella or immediate parasellar area. These approaches have often been used alone or in combination as staged approaches for extensive tumors.

More recently, modifications of the transsphenoidal approach that allow additional exposure of the suprasellar, parasellar, and retroclival spaces have been used for various cranial base lesions. . $2,13,16,19,25,31,34,35,37-40,45,46,50,58,65$ In contrast to traditional cranial base surgical approaches, the endonasal technique offers a direct and minimally invasive approach that allows excellent midline access to and visibility of the suprasellar, retrosellar, and retroclival spaces, while obviating brain retraction. ${ }^{10,13,14,29,42,45,48,50,54,63,66}$ Such approaches have recently been integrated and expanded with the use of the endoscope. In fact, this tool has boosted the use of the 
endonasal technique in skull base surgery, offering the surgeon the ability to visualize the surgical field safely and effectively. Furthermore, the constant improvements in diagnostic imaging techniques and the increasing use of image guidance systems during endoscopic endonasal procedures has provided increasing accuracy and safety for this approach, allowing improved, constant surgical orientation in an anatomically complex area.

Recent anatomical studies and clinical reports have detailed the anatomy encountered in the endoscopic endonasal approach. ${ }^{1,2,6,11,13,14,30-33,48,54,55}$ Full access to the skull base and the cisternal spaces it encloses is possible with this route, which can extend from the crista galli to the spinomedullary junction (Fig. 1), yielding complete visualization of the carotid and vertebrobasilar arterial systems and of all 12 cranial nerves. The technique does require a large opening of the dura mater over the tuberculum sellae and posterior planum sphenoidale, or the retroclival space, and typically results in large intraoperative CSF leaks. This necessitates precise and effective dural closure to prevent a postoperative CSF fistula, with its potential for tension pneumocephalus and meningitis.

We present an anatomical dissection study to define the application of the extended, endoscopic endonasal approach to the midline skull base. The study was performed to understand better the complex anatomical relationships of the structures involved in the approach, and to become more familiar with the endoscopic views and associated skills, which are somewhat different from those used in the traditional, microscopic modality.

\section{SURGICAL ANATOMY OF ENDONASAL APPROACHES}

\section{Anatomical Dissection Material and Endoscopic Equipment}

Five fresh, latex-injected cadaver heads were dissected for the anatomical studies. An endoscopic endonasal approach, which was extended to include the entire midline skull base, was performed in all cases. Endoscopic dissections were performed at the Institute of Anatomy of the University of Vienna by using a rigid endoscope (Karl Storz and Co., Tuttlingen, Germany) that was $4 \mathrm{~mm}$ in diameter, $18 \mathrm{~cm}$ in length, with $0^{\circ}$ lenses. The endoscope was connected to a light source via a fiberoptic cable and to a camera fitted with 3-charge-coupled devices sensors. The video camera was connected to a 21-in monitor supporting the high resolution of the 3-charge-coupled devices technology. To guarantee a suitable file of anatomical images, a digital video recorder system (DVcam) was used.

\section{Standard Endoscopic Approach}

In the standard endoscopic approach to the sellar region, ${ }^{4}$ the endoscope is introduced through the right nostril, close to the floor of the nasal cavity. The first structures to be identified are the inferior turbinate, the middle turbinate, and the nasal septum. The head of the middle turbinate is dislocated laterally to widen further the space between the middle turbinate and the nasal septum and to create an adequate surgical pathway in the posterior nasal cavity (Fig. 2A and $\mathrm{B})$.

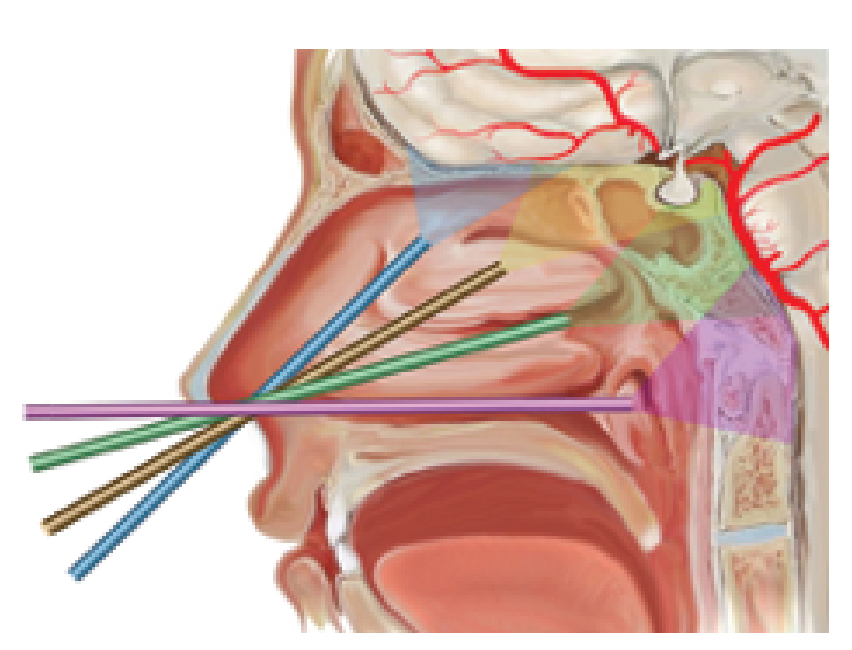

Fig. 1. Schematic drawing showing the different areas of the midline skull base exposed through the endoscopic endonasal approach. The various endoscopic trajectories are illustrated with different colors. Blue marks the endoscopic trajectory to the olfactory groove; yellow shows the trajectory to the sella turcica and planum sphenoidale; green marks the approach to the clivus; and purple shows the trajectory to the craniovertebral junction and foramen magnum.

As the endoscope advances into the nasal cavity, it reaches the choana, which represents the main, inferior landmark of the approach. Its medial margin is the vomer, which confirms the "midline" of the approach, whereas its roof is shaped by the inferior wall of the sphenoidal sinus. Lateral to the choana is the tail of the inferior turbinate. The endoscope is then angled rostrally, along the roof of the choana and the sphenoethmoid recess, until it reaches the sphenoid ostium, which is usually located approximately $1.5 \mathrm{~cm}$ above the roof of the choana (Fig. 2C).

Sometimes, especially in a well-pneumatized sphenoidal sinus, the ostium cannot be visualized because it is covered by the superior (or supreme) turbinate. In these cases, the superior turbinate can be gently lateralized or removed to expose the ostium and gain access to the sphenoidal sinus through its enlargement. If the sphenoid ostium is not visible once the choana is identified, another useful way to gain access to the sphenoid cavity is to advance the endoscope rostrally along the sphenoethmoid recess for approximately $1.5 \mathrm{~cm}$, between the superior turbinate and the nasal septum. Pressure is then applied with a blunt instrument to create access to the sphenoid cavity through this thin portion of the anterior wall.

After identification of the sphenoid cavity, the nasal septum is separated from the sphenoid rostrum. The whole anterior wall of the sphenoidal sinus is enlarged circumferentially, taking care not to enlarge the sphenoidotomy too much in the inferolateral direction, where the sphenopalatine artery and its major branches lie (Fig. 3).

After the anterior sphenoidotomy has been performed, one or more septa inside the sphenoidal sinus are removed. After removal of the sphenoid septa, the posterior and lateral walls of the sphenoidal sinus are visible, with the sellar floor at the center, the sphenoethmoid planum above it, and the sphenoid rostrum and clival indentation/recess below. Lateral to the sellar floor, the osseous prominences of the 

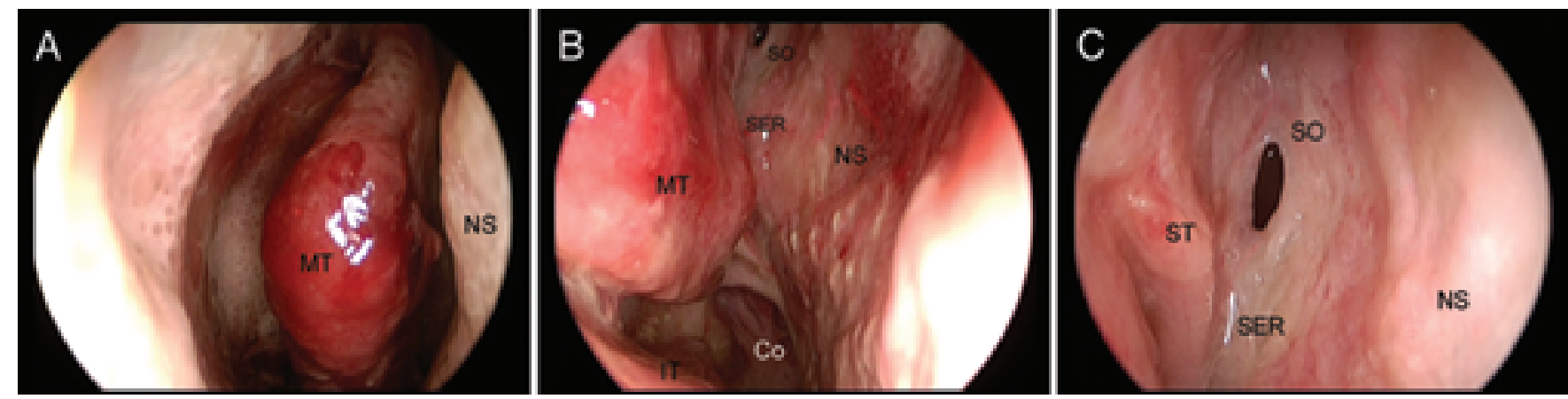

Fig. 2. Endoscopic views obtained in a cadaver showing the standard (right nostril) approach to the sellar region. The nasal step of the procedure is shown, with identification of the landmarks inside the nostril. Co = choana; IT = inferior turbinate; MT = middle turbinate; $\mathrm{NS}=$ nasal septum; $\mathrm{SER}=$ sphenoethmoid recess; $\mathrm{SO}=$ sphenoid ostium; $\mathrm{ST}=$ superior turbinate.

ICA and the optic nerve can be seen, and between them is the opticocarotid recess, molded by the pneumatization of the optic strut of the anterior clinoid process (Fig. 4).

\section{Extended Endoscopic Approaches: Basic Concepts}

The standard endoscopic endonasal transsphenoidal approach to the sellar region is usually accomplished through one nostril with lateralization of the middle turbinate only and an anterior sphenoidotomy. In contrast with the standard endoscopic approach, in which the sphenoidal sinus in the majority of cases provides the surgical space to gain access to the sellar region, the extended approaches require the creation of a wider surgical corridor to expose and work in the different areas around the sella. The creation of such surgical corridors requires removal of the middle turbinate on one side (usually the right one; Fig. 5A), lateralization of the middle turbinate in the other nostril, and removal of the posterior portion of the nasal septum (Fig. 5B). In this way, it is possible to create conditions that allow the use of two or three instruments, in addition to the endoscope,

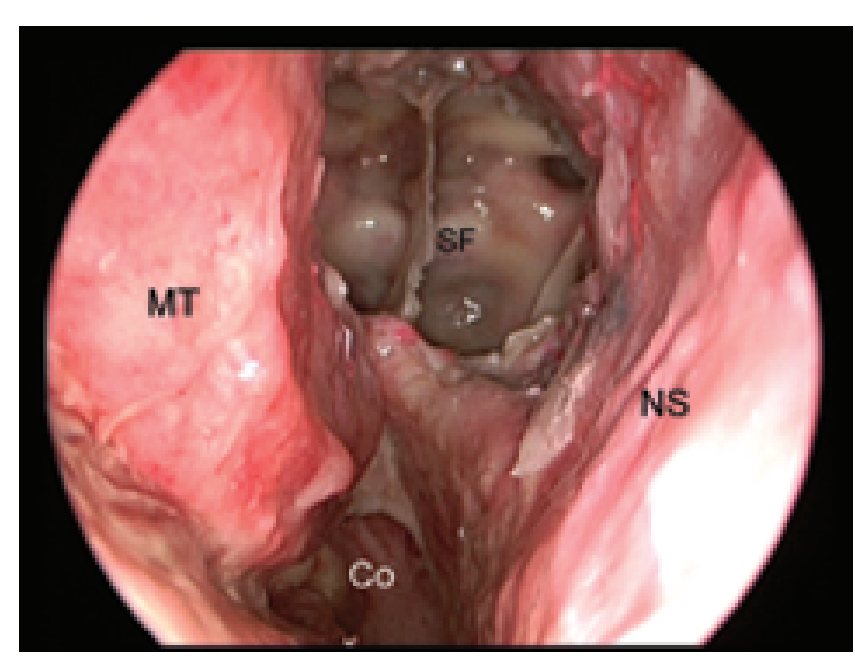

Fig. 3. Endoscopic view obtained in a cadaver, showing the standard approach to the sellar region (sphenoid step of the procedure). The anterior sphenoidotomy has been performed. Note the relationship between the choana and the sphenoid sinus. SF $=$ sellar floor. through both nostrils. In the next steps, other nasal and paranasal structures must be removed according to the different surgical target areas as described later.

Planum Sphenoidale. Access to the suprasellar region and the sphenoid planum is obtained through a more anterior trajectory compared with the one used to reach the sellar region. This route requires a wider opening of the anterior wall of the sphenoidal sinus, which is obtained by removing the superior (supreme) turbinates and the posterior ethmoid air cells located laterally to these turbinates. In the course of such maneuvers, particular attention must be paid to avoid damaging the posterior ethmoidal artery, a branch of the ophthalmic artery that passes through a thin osseous channel along the roof of the ethmoid (Fig. 6A). It is also important not to extend the removal of the nasal septum and the ethmoid too anteriorly, to avoid damaging the olfactory nerve endings or the cribriform plate of the ethmoid.

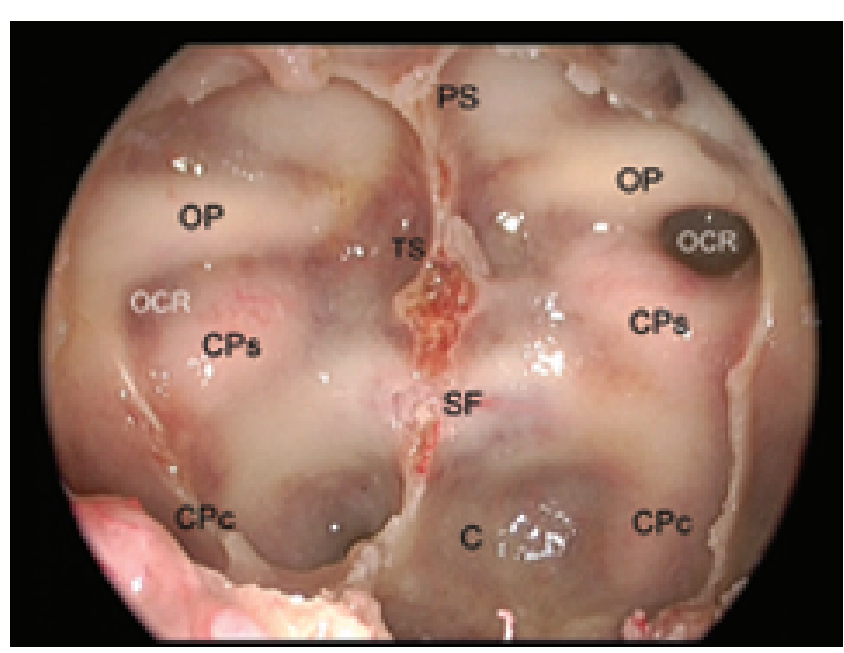

Fig. 4. Endoscopic view obtained in a cadaver, showing the standard approach to the sellar region (sphenoid step of the procedure). The sphenoid septa have been removed to allow identification of all the bone landmarks inside the sphenoid sinus. $\mathrm{C}=$ clivus; $\mathrm{CPc}=$ clival portion of the carotid protuberance CPs $=$ sellar portion of the carotid protuberance; OCR = optocarotid recess; OP = optic protuberance; PS = planum sphenoidale; $\mathrm{TS}=$ tuberculum sellae. 

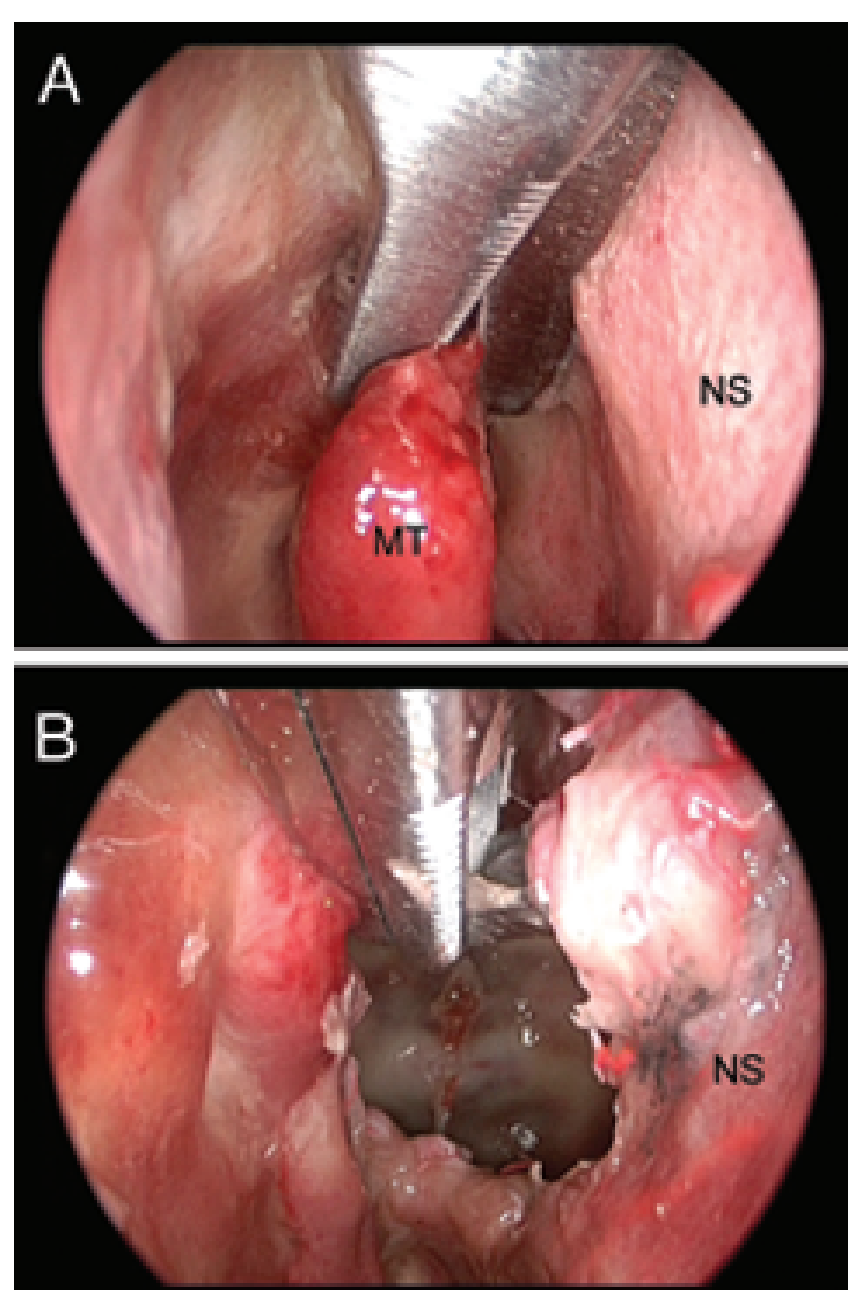

Fig. 5. Endoscopic views obtained in a cadaver, showing basic concepts for extended approaches. A: Middle turbinectomy. $\mathrm{B}$ : Removal of the posterior portion of the nasal septum with a retrograde bone punch.

Once the sphenoid cavity is completely exposed, all of the septa inside it have to be removed up to their attachment to the planum or to osseous prominences such as the optic or carotid prominences. This provides a very wide exposure of the entire sphenoid cavity. Lateral septa often lead directly to the ipsilateral opticocarotid recess, providing an excellent anatomical guide as well as some potential for damage to the associated critical structures.

Above the sellar floor, the angle formed by the convergence of the sphenoid planum with the sellar floor is recognizable; from the intracranial view, this corresponds to the tuberculum sellae. As one moves the endoscope in an anterior direction, the sphenoid planum is visible, laterally delineated by the protuberances of the optic nerves that diverge toward the apices of the orbits.

The opening of the planum starts with the removal of the tuberculum sellae, extended bilaterally in the direction of the opticocarotid recesses. The upper half of the sellar floor and the posterior portion of the planum sphenoidale are removed first, isolating the tuberculum. Once this has been done, the thinned tuberculum is carefully fractured and dis- sected from the dura mater, being careful to avoid entering the superior intercavernous sinus. The removal of the tuberculum sellae and/or the sphenoid planum is extended in a posteroanterior direction for 1.5 to $2 \mathrm{~cm}$, but not beyond the posterior ethmoidal arteries. The lateral extension of the opening is limited by the protuberances of the optic nerves (Fig. 6B).

Next, the dura mater above the pituitary gland is opened, allowing visualization of the intracranial structures. The chiasm and the optic nerves are clearly visible. We can consider two endoscopic surgical corridors, one below the chiasm and one above it (Fig. 7).

Below the chiasm, the pituitary stalk and gland with their vascular supply are visible. Passing the scope between the pituitary stalk and the supraclinoid portion of the ICA, the ventral surface of the chiasm, the optic tract, and the proximal portion of the anterior cerebral artery are all visible (Fig. 8A). After opening the Liliequist membrane by direct-
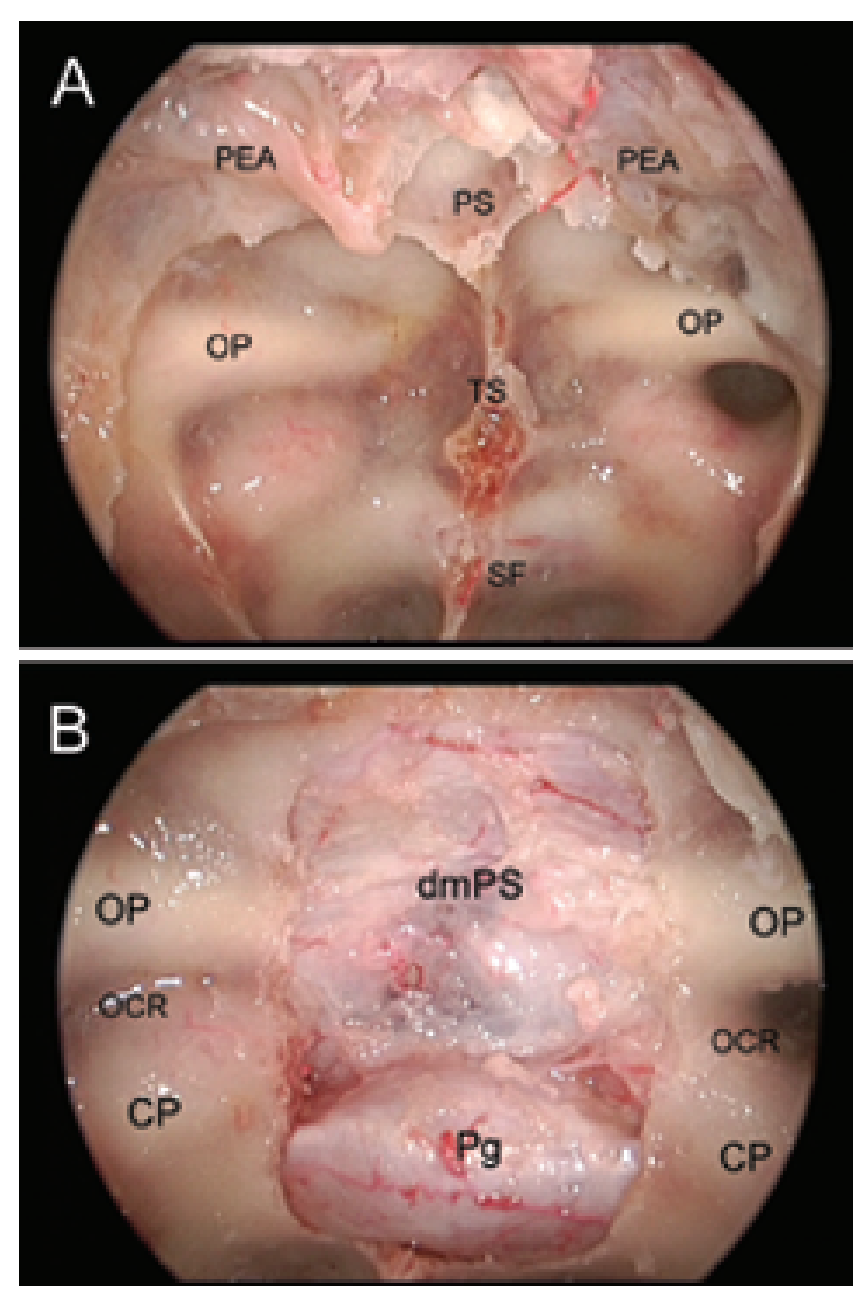

Fig. 6. Endoscopic views obtained in a cadaver, showing the extended approach to the planum sphenoidale. A: Exposure of the planum sphenoidale. The posterior ethmoid cells have been removed to expose the posterior ethmoidal arteries, which represent an important surgical landmark. B: The bone of the tuberculum sellae and the planum sphenoidale have been removed. $\mathrm{CP}=$ carotid protuberance; $\mathrm{dmPS}=$ dura mater of the planum sphenoidale; $\mathrm{PEA}=$ posterior ethmoidal artery; $\mathrm{Pg}=$ pituitary gland. 
ing the endoscope over the dorsum sellae, it is possible to reach the posterior cranial fossa and to expose the upper portion of the brainstem. The VA apex, posterior cerebral arteries, and superior cerebellar arteries, with the third cranial nerves between them, are clearly exposed (Fig. 8B). By angling the endoscope above the chiasm after the lateral displacement of the medial surfaces of the frontal lobes, the anterior part of the circle of Willis is visible (Fig. 9).

Olfactory Groove. The procedure again starts with the removal of the middle turbinate in the right nostril. The bulla ethmoidalis and the anterior and posterior ethmoid cells are opened to identify the lamina papyracea laterally, the floor of the anterior cranial base superiorly, and the nasal septum medially. At this point the superior half of the posterior nasal septum is removed to allow a wide view of the superior portion of the contralateral skull base, without obstruction during insertion of the working instruments. The same steps are repeated in the left nostril (the middle turbinate is only lateralized, not removed, on the left). Now the portion of the anterior skull base spanning the distance between the two orbits is exposed (Fig. 10).

The superior portion of the lamina papyracea is removed, and the anterior and posterior ethmoidal arteries are isolated and ligated on both sides (Fig. 11A). The bone of the anterior skull base between the orbits is removed (Fig. 11B) and the dura mater is opened, allowing exposure of the intracranial contents. The olfactory nerves and the basal surfaces of the frontal lobes are initially visualized (Fig. 12A). By retracting the medial surfaces of the frontal lobes, it is possible to expose the two pericallosal arteries in the interhemispheric fissure (Figs. 12B and 13).

Clivus. Access to the clivus is achieved via a more caudal trajectory than is necessary for access to the sellar region. Along such a trajectory, the vomer and the inferior wall (floor) of the sphenoidal sinus are found. Depending on its degree of pneumatization, the sphenoid floor will divide the

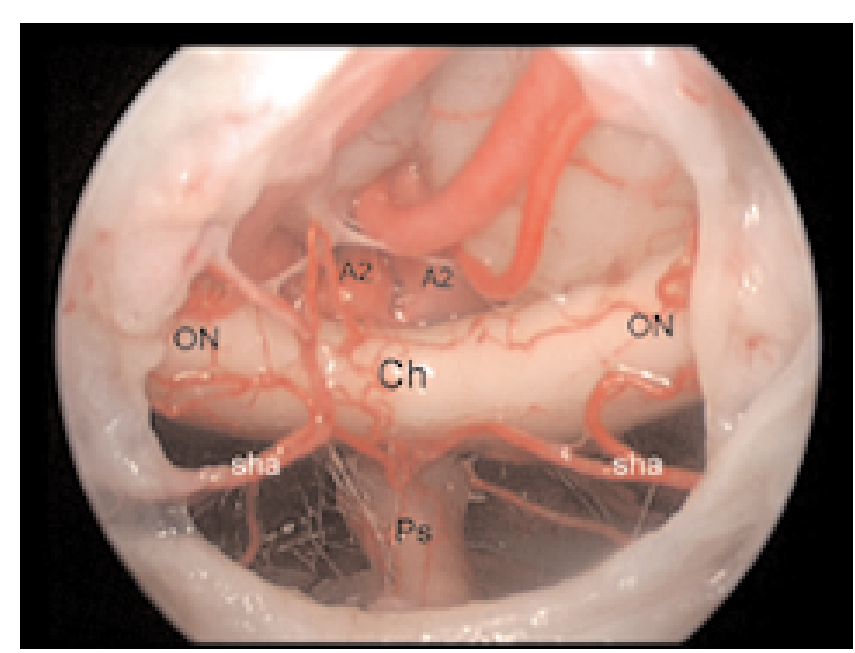

Fig. 7. Endoscopic view obtained in a cadaver, showing the extended approach to the planum sphenoidale (intradural exploration). The chiasm and the optic nerves are at the center of the view, with the anterior part of the circle of Willis above them and the pituitary stalk below. $\mathrm{A} 2=\mathrm{A}_{2}$ segment of the anterior cerebral artery; $\mathrm{Ch}=$ chiasm; $\mathrm{ON}=$ optic nerve; $\mathrm{Ps}=$ pituitary stalk; sha = superior hypophyseal artery.
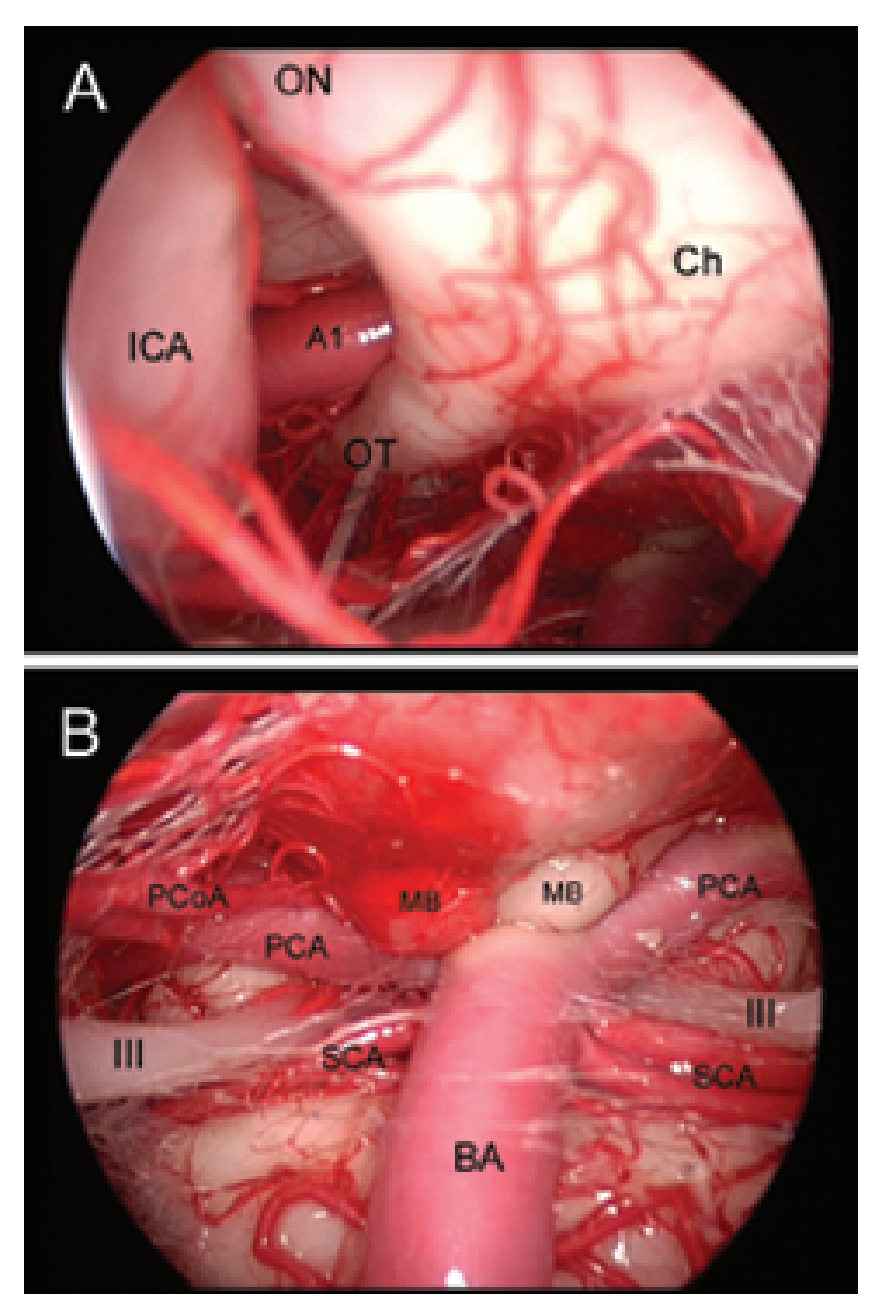

Fig. 8. Endoscopic views obtained in a cadaver, showing the extended approach to the planum sphenoidale (intradural exploration). The endoscope has been advanced below the chiasm. A: Passing with the scope between the pituitary stalk and the supraclinoid portion of the right internal carotid artery, the right $\mathrm{A}_{1}$ segment of the anterior cerebral artery and the right optic tract are visible. B: Directing the endoscopic vision backward, the basilar apex and the closer neurovascular structures are exposed. $\mathrm{A} 1=\mathrm{A}_{1}$ segment of the anterior cerebral artery; $\mathrm{BA}=$ basilar artery; ICA = internal carotid artery (supraclinoid segment); III = oculomotor (third cranial) nerve; $\mathrm{MB}=$ mammillary body; OT = optic tract; $\mathrm{PCA}=$ posterior cerebral artery $\mathrm{PCoA}=$ posterior communicating artery; SCA = superior cerebellar artery.

sphenoid portion of the clivus from the rhinopharyngeal segment, in variable proportions. Entry into the posterior cranial fossa through the clivus is most easily gained in patients with a retrosellar-type sphenoidal sinus. In these cases, the clivus is thinner than in patients with a conchaltype structure.

The preliminary steps of the procedure include the previously described middle turbinectomy on the side of the approach (usually the right), wide anterior sphenoidotomy with removal of all septa, and removal of the posterior portion of the nasal septum to allow a binasal approach (Fig. 14A). The nasal mucosa is detached from the vomer and along the inferior wall (floor) of the sphenoidal sinus. The 


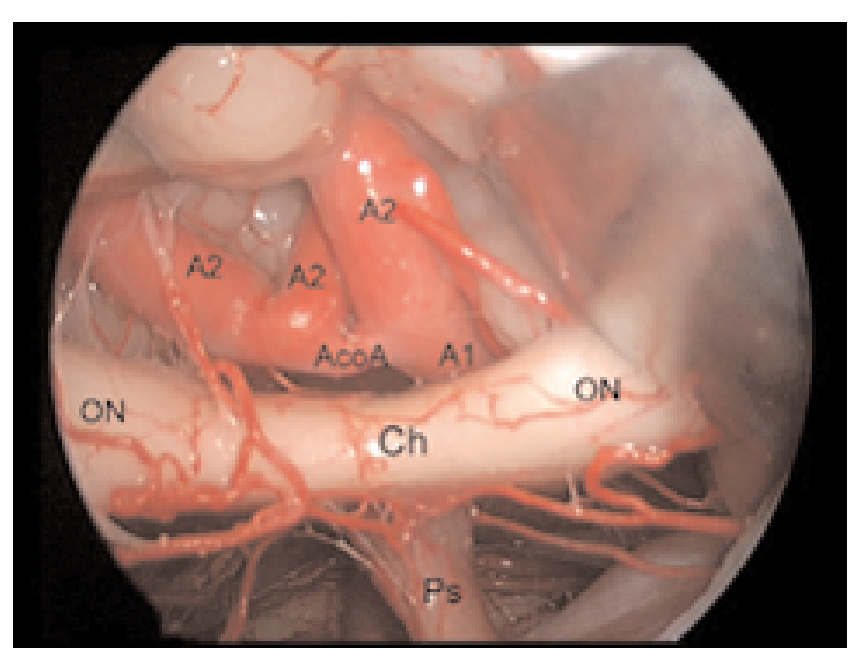

Fig. 9. Endoscopic view obtained in a cadaver, showing the extended approach to the planum sphenoidale (intradural exploration). The endoscope has been advanced above the chiasm. The anterior part of the circle of Willis is visible. Note the presence of a trifurcation of the anterior cerebral artery. $\mathrm{ACoA}=$ anterior communicating artery; $\mathrm{CH}=$ chiasm.

mucosa is dissected laterally until the vidian nerves are identified; this represents the lateral limits of the surgical corridor (Fig. 14B).

The vomer and the floor of the sphenoidal sinus are completely removed, permitting the union of the sphenoidal and rhinopharyngeal parts of the clivus. The mucosal flap obtained from the dissection of the vomer and the inferior wall of the sphenoidal sinus is cut just medial to the vidian nerves, down to the floor of the nasal cavity inferiorly. There it is separated from the rhinopharyngeal mucosa, thus creating a mucosal flap that can be reflected superior-

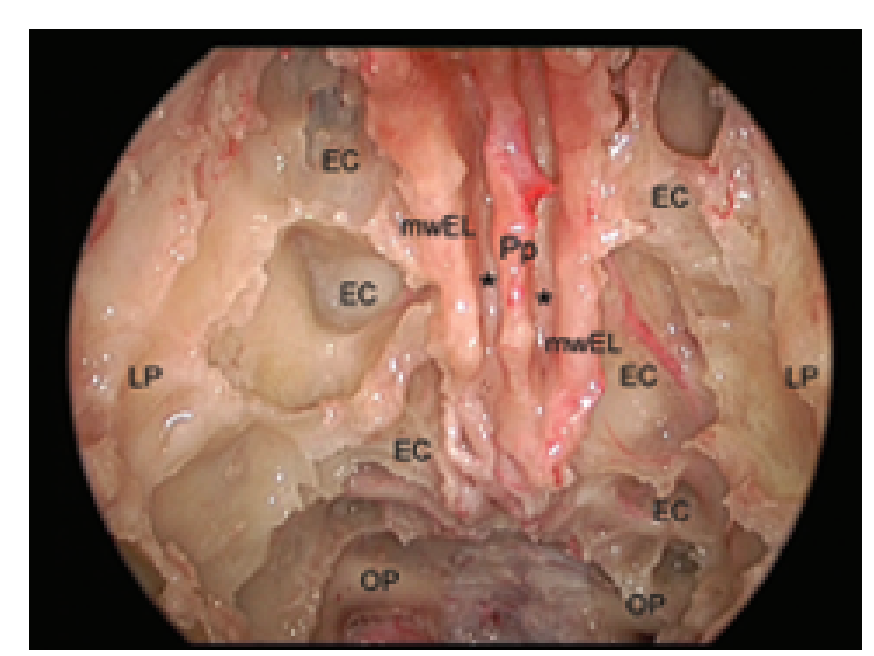

Fig. 10. Endoscopic view obtained in a cadaver, showing the extended approach to the olfactory groove. The superior portions of the nasal septum, ethmoid cells, and middle turbinate on both sides have been removed to expose the cribriform plate. The asterisks mark the olfactory groove. $\mathrm{EC}=$ ethmoid cell; $\mathrm{LP}=$ lamina papyracea; $\mathrm{mwEL}=$ medial wall of the ethmoid labyrinth; $\mathrm{Pp}=$ perpendicular plate of the ethmoid. ly, making it available for closure of the surgical defect (Fig. 15). At this stage, the clivus is exposed from the level of the pituitary gland down to that of the eustachian tubes. The fascia covering the clivus is extremely tough and adherent and can be difficult to remove. Depending on the extension of the lesion, the bone of the clivus is more or less extensively removed. Using the endoscopic endonasal approach, the limits of the clival fenestration are represented by the sella superiorly and by the paraclival tracts of the ICA laterally. Inferiorly, below the level of paraclival carotid arteries, there are no relevant vascular structures limiting the lateral bone removal of the clivus, thus allowing a wider exposure of the surgical field. It is important, however, to remain aware of the location of the retropharyngeal carotid arteries, which are deep and variably lateral to the eustachian tubes. Usually well lateral, the carotid artery at this level will occasionally take a more medial course.

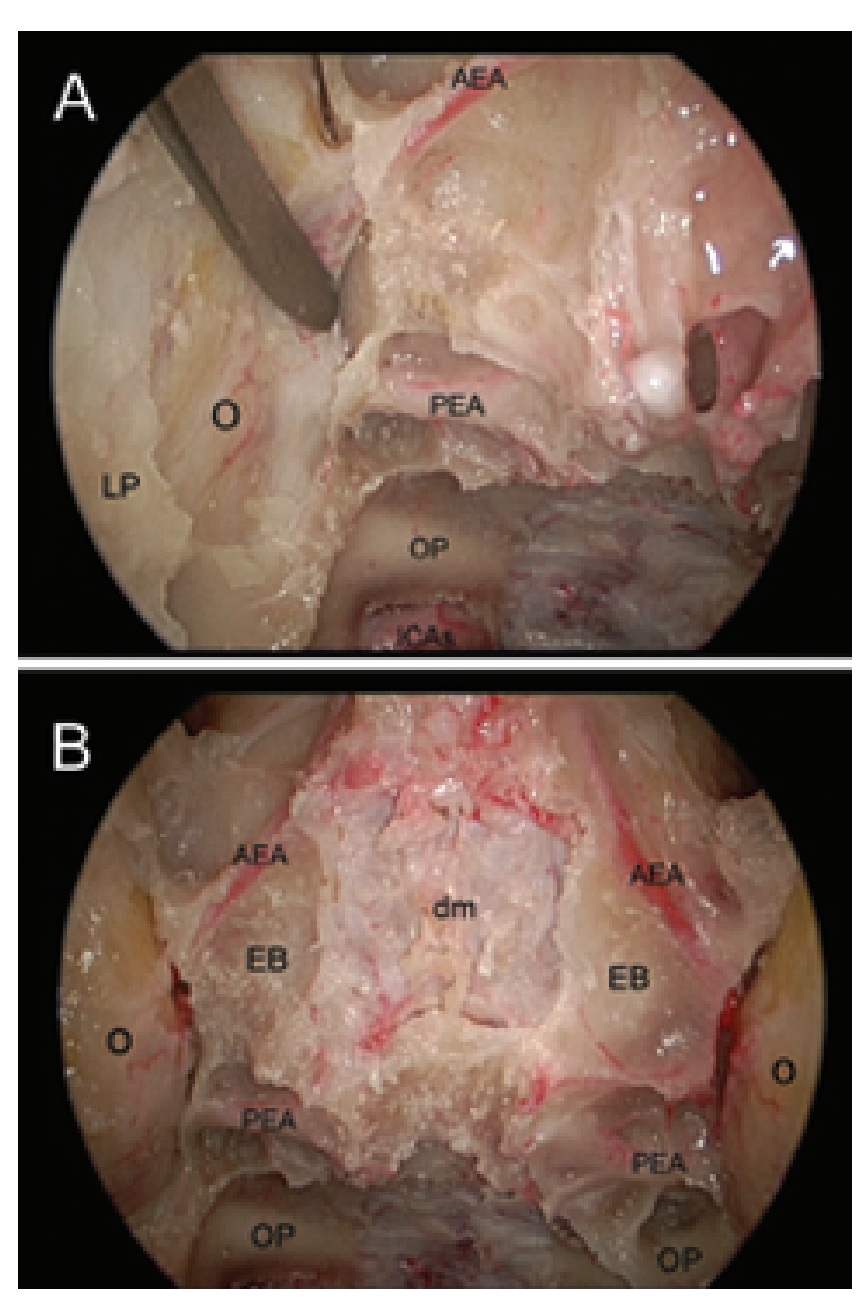

Fig. 11. Endoscopic views obtained in a cadaver, showing the extended approach to the olfactory groove. A: The right lamina papyracea has been partially removed in its superior portion to allow the identification of the ethmoidal arteries. B: The ethmoidal arteries have been isolated on both sides and the cribriform plate has been partially removed, thus exposing the dura mater. $\mathrm{AEA}=$ anterior ethmoidal artery; $\mathrm{dm}=$ dura mater; $\mathrm{ICAs}=$ sellar portion of the ICA; $\mathrm{O}=$ orbit. 

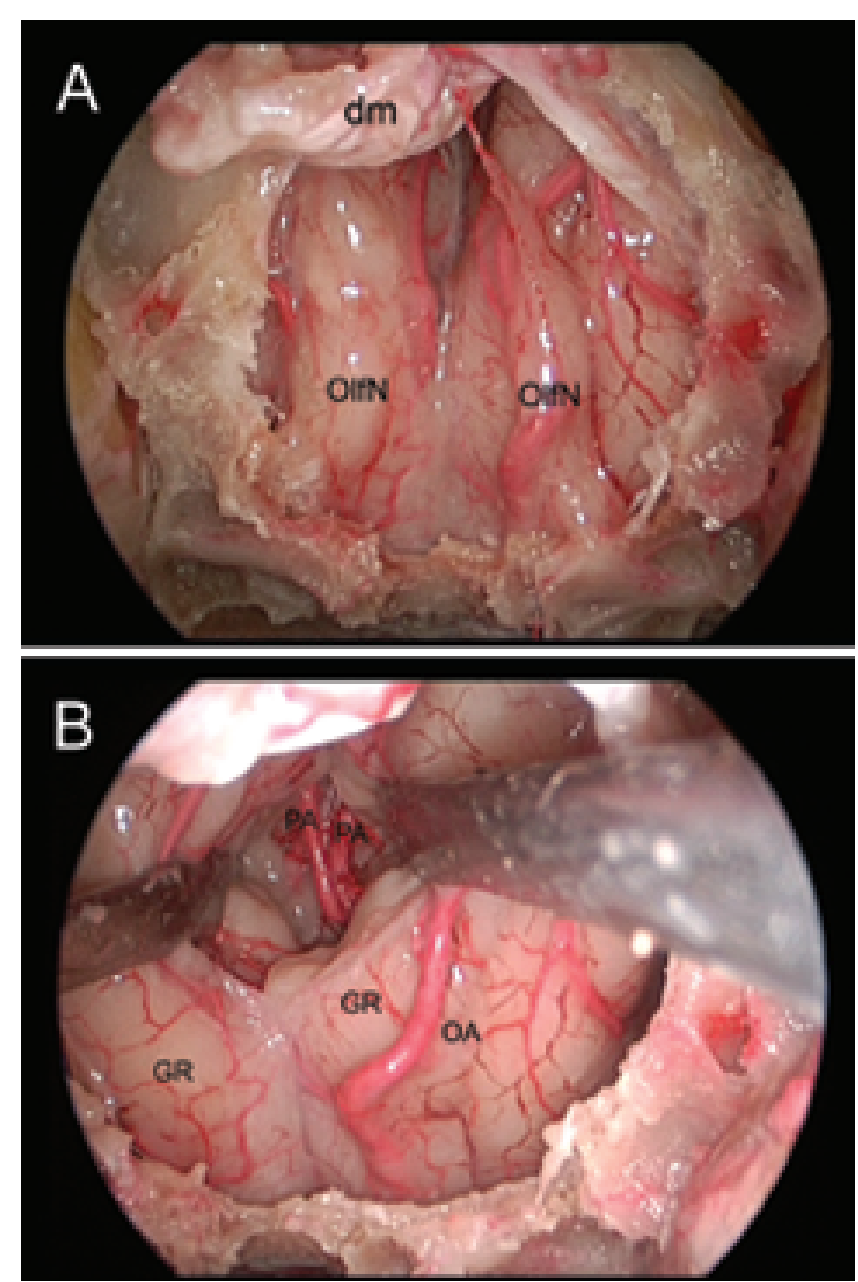

Fig. 12. Endoscopic views obtained in a cadaver, showing the extended approach to the olfactory groove. A: The dura mater has been opened and the intracranial contents exposed. B: By splitting the interhemispheric fissure, the pericallosal arteries are visualized. $\mathrm{GR}=$ gyrus rectus; $\mathrm{OA}=$ orbital artery; OlfN = olfactory nerve; $\mathrm{PA}=$ pericallosal artery.

The clivus contains the basilar plexus, which is the most extensive series of intercavernous venous connections across the midline. The superior and inferior petrosal sinuses join the basilar plexus. The abducent nerve enters the cavernous sinus by passing through the basilar sinus close to the paraclival tract of the ICA; therefore, particular attention should be paid during bone removal in this already complicated area (Fig. 16). The dorsal meningeal artery, a branch of the meningohypophyseal artery, provides the arterial blood supply to the dura mater of the clival region, and its course is in proximity to that of the abducent nerve.

After the dura mater is opened, the VA and its branches as well as the upper cranial nerves are well visualized along their courses in the posterior cranial fossa (Fig. 17).

Craniovertebral Junction and Anterior Portion of the Foramen Magnum. This approach can be considered the extreme inferior extension of the previously described endoscopic approach to the clivus. The first steps of the procedure are in fact the same as for the endoscopic approach to the cli-

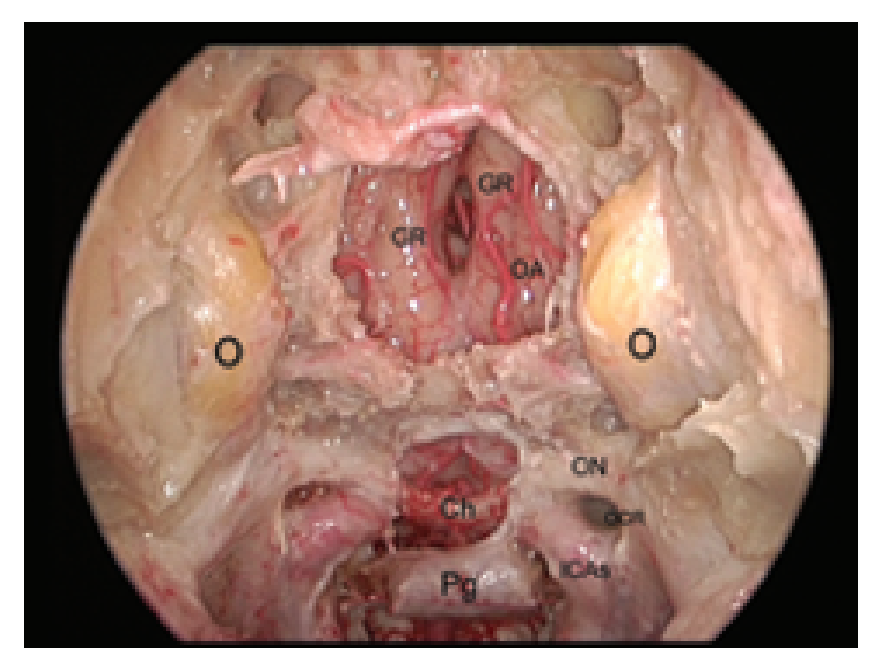

Fig. 13. Endoscopic view obtained in a cadaver, showing a panoramic view of the anterior midline cranial base after removal of the planum sphenoidale and the olfactory groove and opening of the dura mater. Note the course of the optic nerves from the chiasm to the orbit. OCR = opticocarotid recess.

vus. The middle turbinectomy, the removal of the posterior portion of the nasal septum, the wide sphenoidotomy up to the identification of the vidian nerves and the removal of the vomer and the inferior wall/floor of the sphenoidal sinus are performed in the same manner as in the extended endoscopic approach to the clivus.

The main difference consists of the complete removal of the vomer, extending inferiorly, down to the hard palate. This is done to allow the widest exposure of the rhinopharynx and to avoid any conflict among the instruments during the next surgical steps (Fig. 18A). The lower third of the clivus is removed out to the occipital condyles, and the foramen lacerum on both sides is identified because it represents the lateral limit of the approach (Fig. 18B).

Once a wide surgical corridor has been created, the mucosa of the rhinopharynx is removed and the atlantooccipital membrane, longus capitis and longus colli muscles, and the anterior atlas and axis are exposed (Fig. 19). The anterior arch of the atlas is removed, the dens is exposed (Fig. 20), and it is thinned using the microdrill. The dens is then separated from the apical and alar ligaments, dissected from the transverse ligament, and finally removed. At this point, a wide surgical corridor allowing access to the anterior portion of the foramen magnum has been created (Fig. 21).

After the opening of the dura mater, all the neurovascular structures running through the anterior part of the foramen magnum can be visualized. The VAs can be explored from their entrance in the vertebral canal up to the VA (Fig. 22). The two branches of the intradural segment of the VA (the posterior inferior cerebellar artery and the anterior/ventral spinal artery) are visible as well. The hypoglossal nerve can be identified behind the first tract of the intradural VA. This nerve arises along the front of the inferior olive as a series of rootlets that converge on the dural orifice of the hypoglossal canal (Fig. 23A). Below the entrance of the VA, the dentate ligament and the ventral rootlets of the first and second spinal nerves can be visualized in the spinal canal.

Passing the endoscope superior and posterior to the VA, 

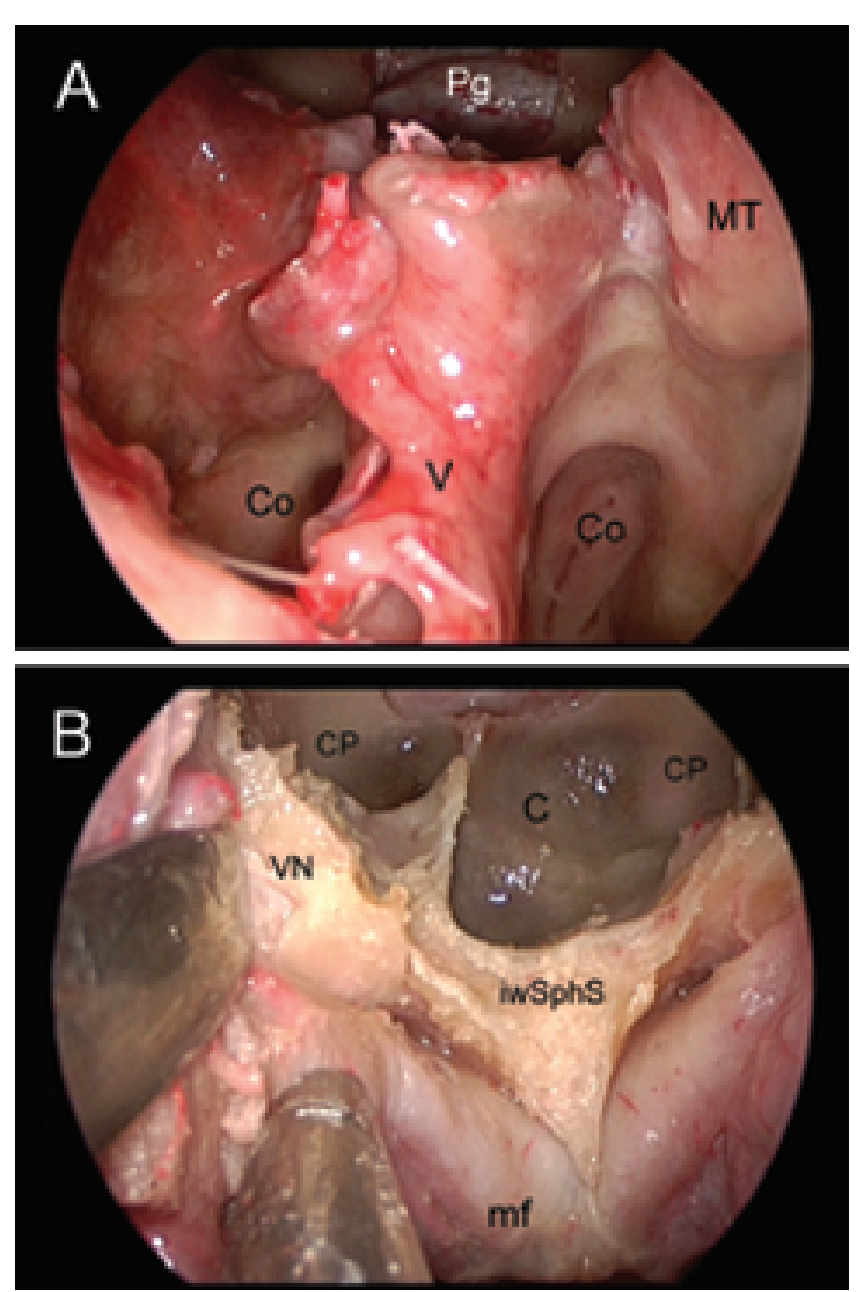

Fig. 14. Endoscopic views obtained in a cadaver, showing the extended approach to the clivus (nasal and sphenoidal steps of the procedure). A: The posterior portion of the nasal septum and the right middle turbinate have been removed, and the anterior sphenoidotomy has been already performed to allow a bilateral approach. Note the two choanae in the same endoscopic view. B The nasal mucosa has been dissected around the vomer and laterally toward the right vidian canal to identify the vidian nerve, which is an important surgical landmark. iwSphS = inferior wall of the sphenoid sinus; $\mathrm{mf}=$ mucosal flap obtained from the mucosa covering the vomer and the inferior wall of the sphenoid sinus; $\mathrm{V}=$ vomer; $\mathrm{VN}=$ vidian nerve.

the lower cranial nerves and the acoustic-facial bundle (seventh and eighth cranial nerves) are explored along with the anterior inferior cerebellar artery (Figs. 23B and 24).

\section{DISCUSSION}

The midline skull base is an anatomical area that extends from the anterior limit of the cranial fossa down to the anterior border of the foramen magnum. It is commonly divided into three parts: 1) the anterior cranial base, which covers the upper nasal cavity and the sphenoidal sinus, and is composed of the crista galli and the cribriform plate of the ethmoid bone and the sphenoid body; 2) the middle cranial base, which is formed by the body of the sphenoid bone, the tuberculum sellae, the pituitary fossa, the anterior and
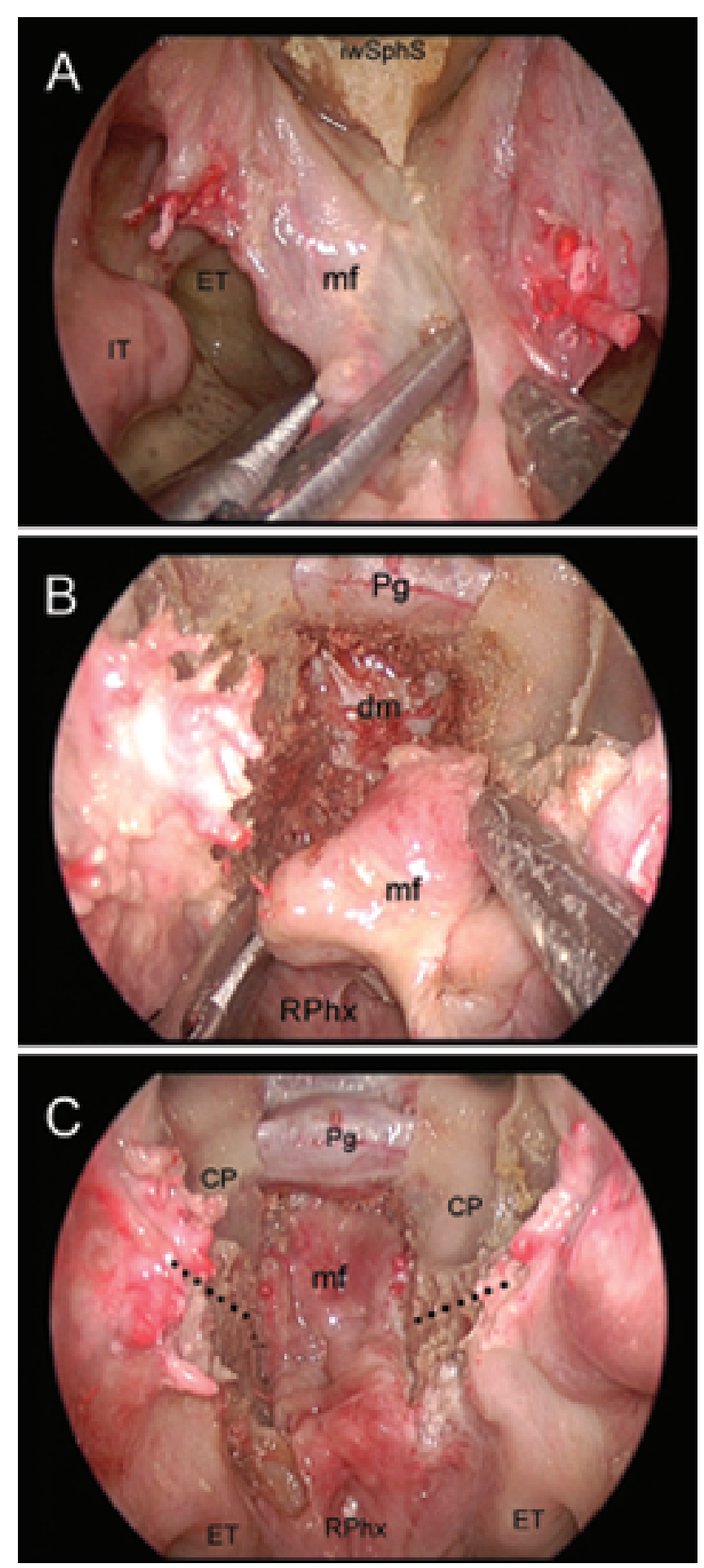

Fig. 15. Endoscopic views obtained in a cadaver, showing the extended approach to the clivus (nasal and sphenoidal steps of the procedure; preparation of a pedicled mucosal flap). A: After removal of the vomer the mucosa is cut along the floor of the nasal cavity. B: After removal of the inferior wall/floor of the sphenoid sinus, the mucosa is cut medial to the vidian nerve. $\quad \mathrm{C}$ : The mucosal flap has been reflected superiorly, over the clivus between the two carotid protuberances. The black dotted lines show the level of the vidian nerves. $\mathrm{dm}=$ dura mater of the clivus; $\mathrm{ET}=$ eustachian tube; $\mathrm{RPhx}=$ rhinopharynx. 

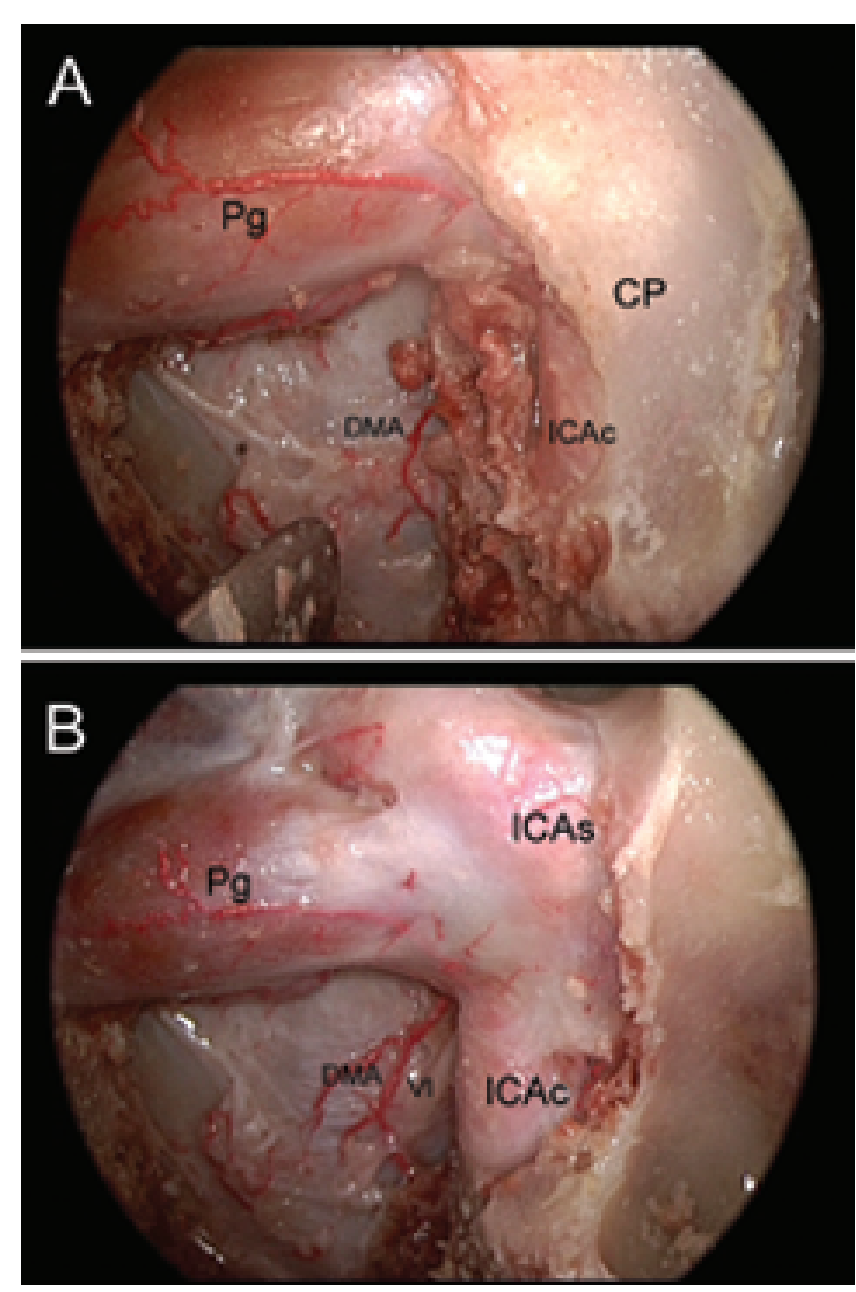

Fig. 16. Endoscopic views obtained in a cadaver, showing the extended approach to the clivus and identification of the abducent nerve. A: The bone of the clivus and the osseous protuberance of the intracavernous carotid artery have been partially removed to identify the dorsal meningeal artery. B: After complete removal of the osseous protuberance of the intracavernous carotid artery, the abducent nerve and its close relationships with the dorsal meningeal artery are visible. Note the abducent nerve passing behind the paraclival segment of the intracavernous carotid artery. DMA $=$ dorsal meningeal artery; ICAc $=$ paraclival tract of the intracavernous carotid artery; ICAs = parasellar tract of the ICA; $\mathrm{VI}=$ abducent nerve.

posterior clinoid processes, the carotid sulcus, and the dorsum sellae; and 3) the posterior cranial base, which extends from the dorsum sellae to the anterior border of the foramen magnum. ${ }^{44,57}$

The extended endoscopic endonasal route, given its versatility, ${ }^{13}$ offers the possibility of exposing the entire midline skull base from below, with the advantage of passing through a less delicate structure (nasal cavity) to reach a more noble one (the brain with its neurovascular structures). Furthermore, the endoscope enables the surgeon to work on tumors located in supra-, para-, retro-, and infrasellar regions under direct visual control. Due to the strategically ideal location of the sphenoidal sinus, the portion of the cranial base extending from the posterior planum sphe-
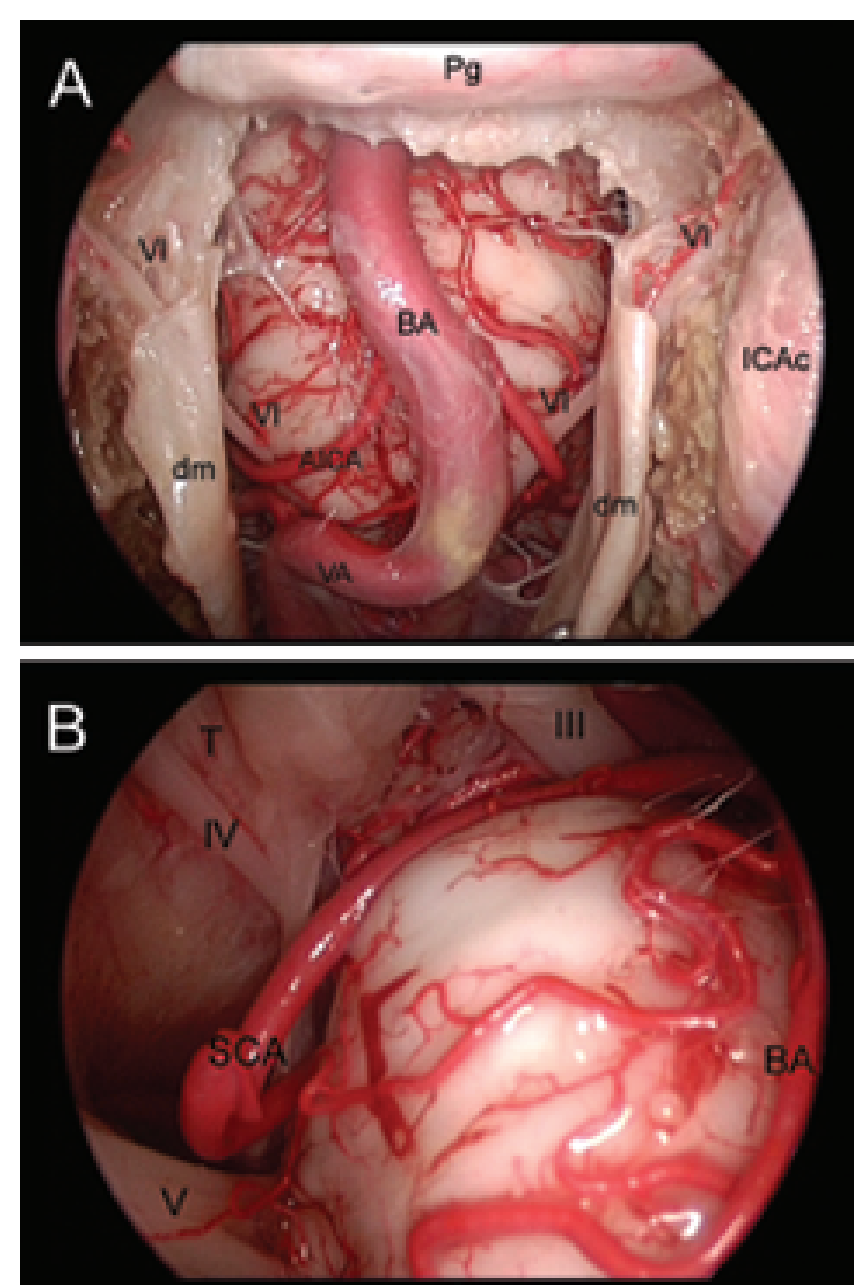

Fig. 17. Endoscopic views obtained in a cadaver, showing the extended approach to the clivus (intradural step) A: After opening the dura mater, the basilar artery and the pons are clearly exposed. The course of the abducent nerve from its origin to the cavernous sinus is also visible. B: With the close-up view, endoscopic view, it is possible to see the origin of the upper cranial nerves, from the oculomotor to the trigeminal nerve. AICA $=$ anterior inferior cerebellar artery; IV = trochlear (fourth cranial) nerve; $\mathrm{T}=$ tentorium; $\mathrm{V}=$ trigeminal (fifth cranial) nerve.

noidale to the upper two thirds of the clivus can be exposed with the endoscopic endonasal approach passing through this aerated cavity, depending on its grade of pneumatization. On the other hand, the anterior portion of the cranial base is reached with a different trajectory, through the bulla ethmoidalis and the anterior and posterior ethmoidal air cells, identifying the lamina papyracea. Finally, the caudal portion of the midline, the posterior cranial base, is exposed through a lower trajectory, which involves the removal of the vomer.

In contrast with the standard endoscopic endonasal, transsphenoidal approach for sellar lesions, the surgical corridors for the extended approaches require removal of the middle turbinate on one side (usually the right one), lateralization of the middle turbinate in the other nostril, and removal of the posterior portion of the nasal septum. This variation will allow the use of both nostrils for access, with two 

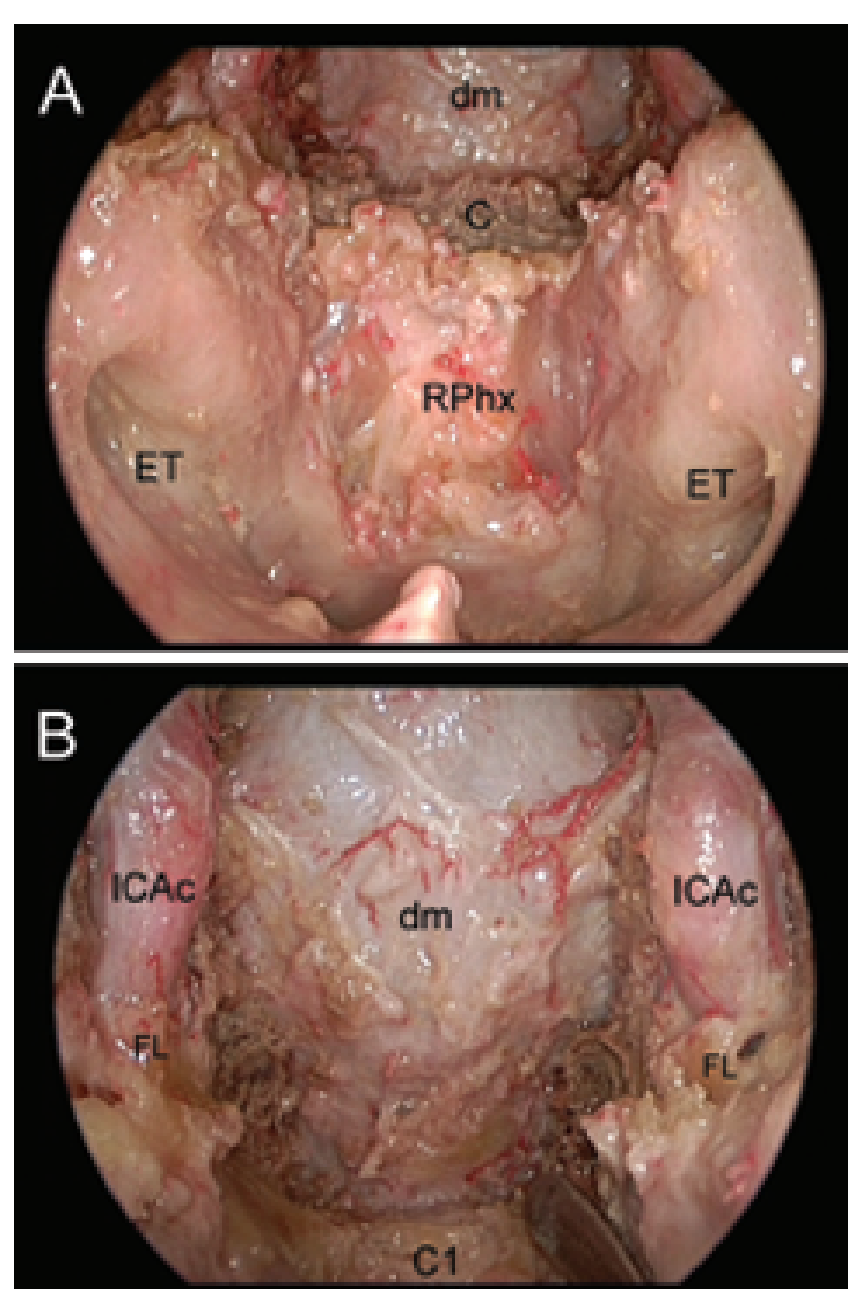

Fig. 18. Endoscopic views obtained in a cadaver, showing extended approach to the craniovertebral junction and anterior portion of the foramen magnum. A: The nasal and sphenoidal step of the procedure have already been performed. A wide view on the rhinopharynx from one eustachian tube to the other has to be obtained before approaching the craniovertebral junction. B: The lower portion of the clivus has been removed and the basal cartilage of the foramen lacerum has been identified. The latter is an important surgical landmark because represents the lateral limits of the approach at this level. $\mathrm{C} 1=$ atlas; $\mathrm{FL}=$ basal cartilage of the foramen lacerum.

or three instruments inserted in addition to the endoscope, which is used freehand by the assistant, because it needs to be continuously moved to expose and reach all the possible areas, and to provide a sense of depth and perspective.

Most of the published results on the extension of the endonasal approach are those involving the suprasellar area and the posterior portion of the planum sphenoidale., ${ }^{9,13,16,19 \text {, }}$ $25,34,35,37,38,40,58,65$ In fact, since the introduction of the extended endonasal approach, ${ }^{65}$ wherein the bone of the tuberculum sellae and posterior planum sphenoidale between the optic canals is removed, suprasellar lesions that traditionally have been approached transcranially, such as meningiomas in the tuberculum sellae, Rathke cleft cysts, and craniopharyngiomas, increasingly have been removed transsphenoidally. Provided that the chiasm is not prefixed and located direct- ly between the sphenoidal sinus and tumor, or that a functional pituitary gland is not directly impeding the transsphenoidal route, the most significant advantages of this approach are the following three: 1) brain retraction is obviated, with an indisputable reduction in surgical morbidity and mortality rates; 2) direct manipulation of the optic apparatus is minimized, with the possibility of lower rates of postoperative visual loss; and 3) early identification of the pituitary gland and infundibulum is provided, which increases the likelihood of preserving neuroendocrine function. Furthermore, because these lesions generally displace the optic apparatus away from the surgeon, with this approach the tumor removal can begin immediately after opening the dura mater, resulting in prompt chiasmal decompression. ${ }^{16}$ Chiasm or gland displacement into the
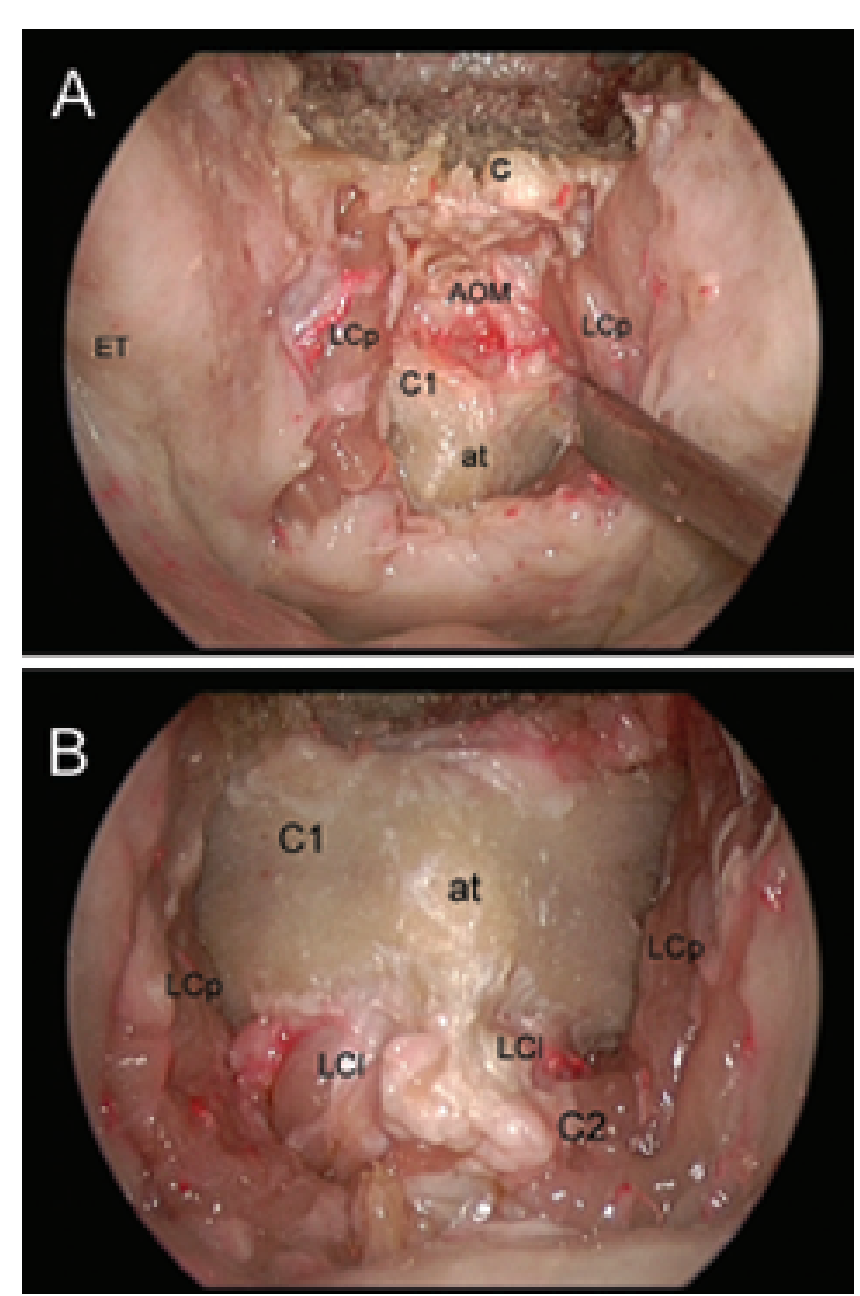

Fig. 19. Endoscopic views obtained in a cadaver, showing the extended approach to the craniovertebral junction and anterior portion of the foramen magnum. A: The mucosa of the rhinopharynx has been removed and the longus capitis and longus colli muscles have been dissected to expose the craniovertebral junction. Note the relationship of the eustachian tube with the atlas. B: Endoscopic close-up view showing the exposure of the craniovertebral junction. $\mathrm{AOM}=$ anterior atlantooccipital membrane; at $=$ anterior tubercle; $\mathrm{C} 2$ = axis; $\mathrm{LCl}=$ longus colli muscle; $\mathrm{LCp}=$ longus capitis muscle. 

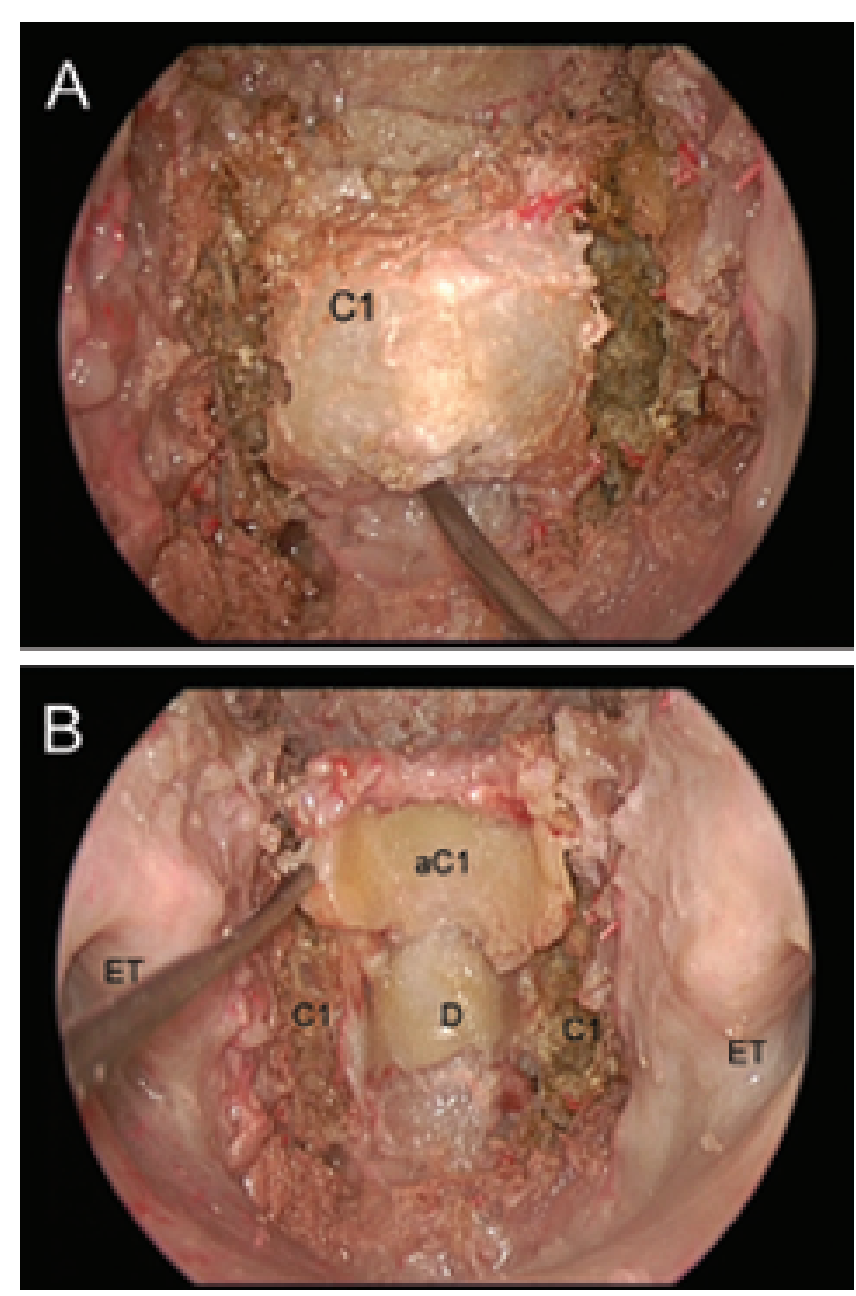

Fig. 20. Endoscopic views obtained in a cadaver, showing the extended approach to the craniovertebral junction and the anterior portion of the foramen magnum. A: The anterior arch of the atlas has been drilled bilaterally. B: The anterior arch of the atlas has been reflected superiorly, exposing the dens. $\mathrm{aC} 1=$ anterior arch of $\mathrm{C}-1$ reflected superiorly; $\mathrm{D}=$ dens.

transsphenoidal surgical pathway is rare and is not a contraindication. This situation would, however, require some further extension of the approach, in addition to the need for greater care to avoid injury to these structures.

In contrast to other skull base approaches, such as anterior, anterolateral, and posterolateral routes, which are routinely described for accessing extraaxial lesions ventral to the brainstem, $3,7,8,15,23,24,27,28,36,41,43,49,52,53,56,59-62,64$ the endonasal approach to the clival area has been used historically only to remove clival chordomas. ${ }^{13,39,45,46}$ The bone destruction related to the chordoma often creates the surgical pathway, and its location is often purely anterior, making the transsphenoidal approach less difficult. Only more recent technical reports have described the possibility of using the transsphenoidal approach to remove lesions such as epidermoid cysts in the retroclival area, in front of the brainstem. ${ }^{17}$ In addition, the endonasal approach to the clivus has been boosted by the introduction of the endoscope to this surgery. Furthermore, with this anatomical study we have
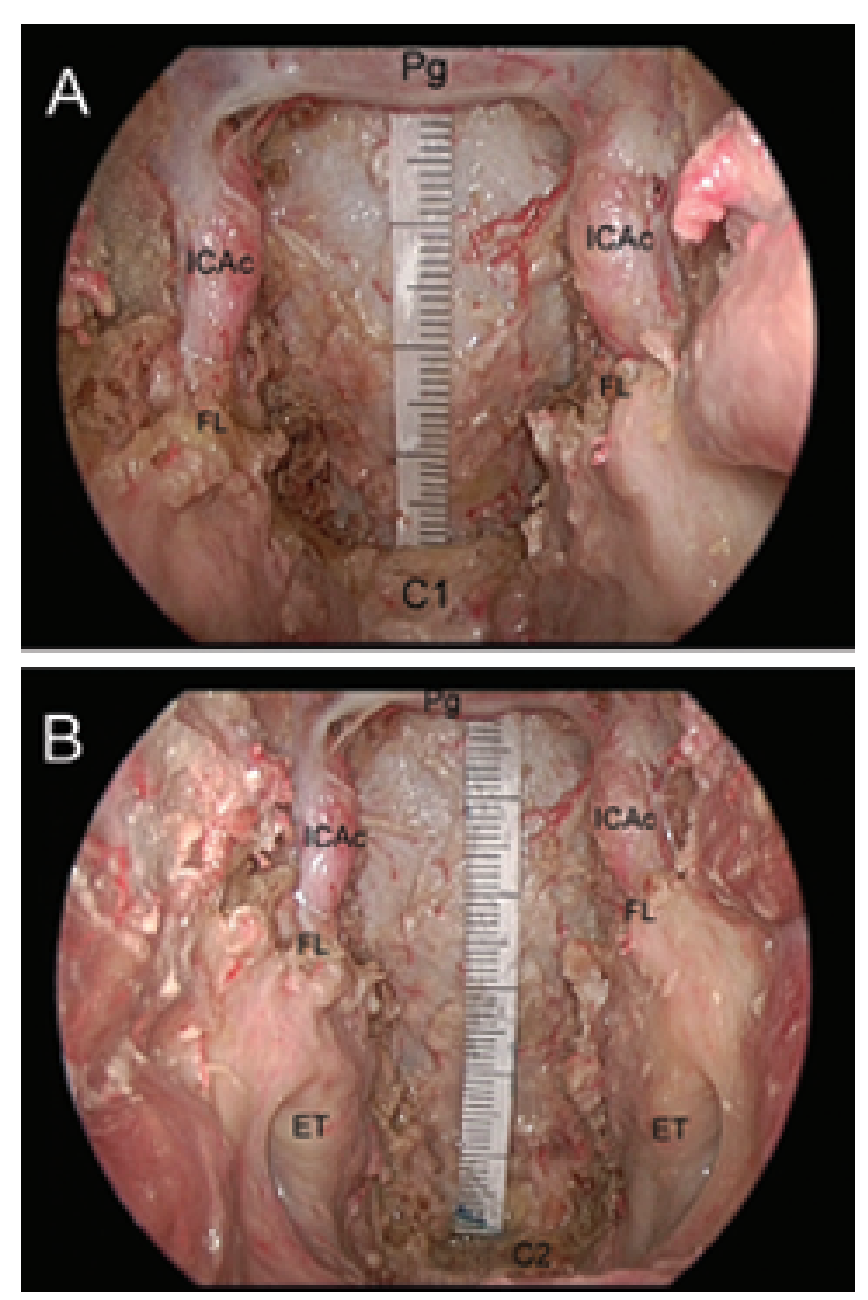

Fig. 21. Endoscopic views obtained in a cadaver, showing the extended approach to the craniovertebral junction and anterior portion of the foramen magnum. A comparison was done of the length of the surgical field after complete removal of the clivus (A) and after the additional removal of the craniovertebral junction (B). To remove the clivus, the length of the surgical field starting from the pituitary gland is approximately $4 \mathrm{~cm}$, whereas with the additional removal of the craniovertebral junction it becomes approximately $6 \mathrm{~cm}$.

demonstrated that the endoscopic endonasal technique can expose not only the upper two thirds of the clivus, but also the entire lower skull base, down to the foramen magnum and even the odontoid process of C-2. The VA and its branches in the basal cistern, as well as the neighboring cranial nerves, are well visualized along almost their entire courses. With this approach it might be possible to treat intradural lesions located anterior and anterolateral to the brainstem and upper spinal cord, which present a considerable challenge with any approach. In fact, the endoscopic endonasal approach allows the extension of bone removal at the level of foramen magnum, out to the hypoglossal canal and the dural entrance of the VA in the spinomedullary canal. Furthermore, the endonasal approach permits access to the lower clivus and foramen magnum without ever requiring an incision in the soft palate or the use of tracheostomy, with obvious potential advantages in terms of surgery-related morbidity. 

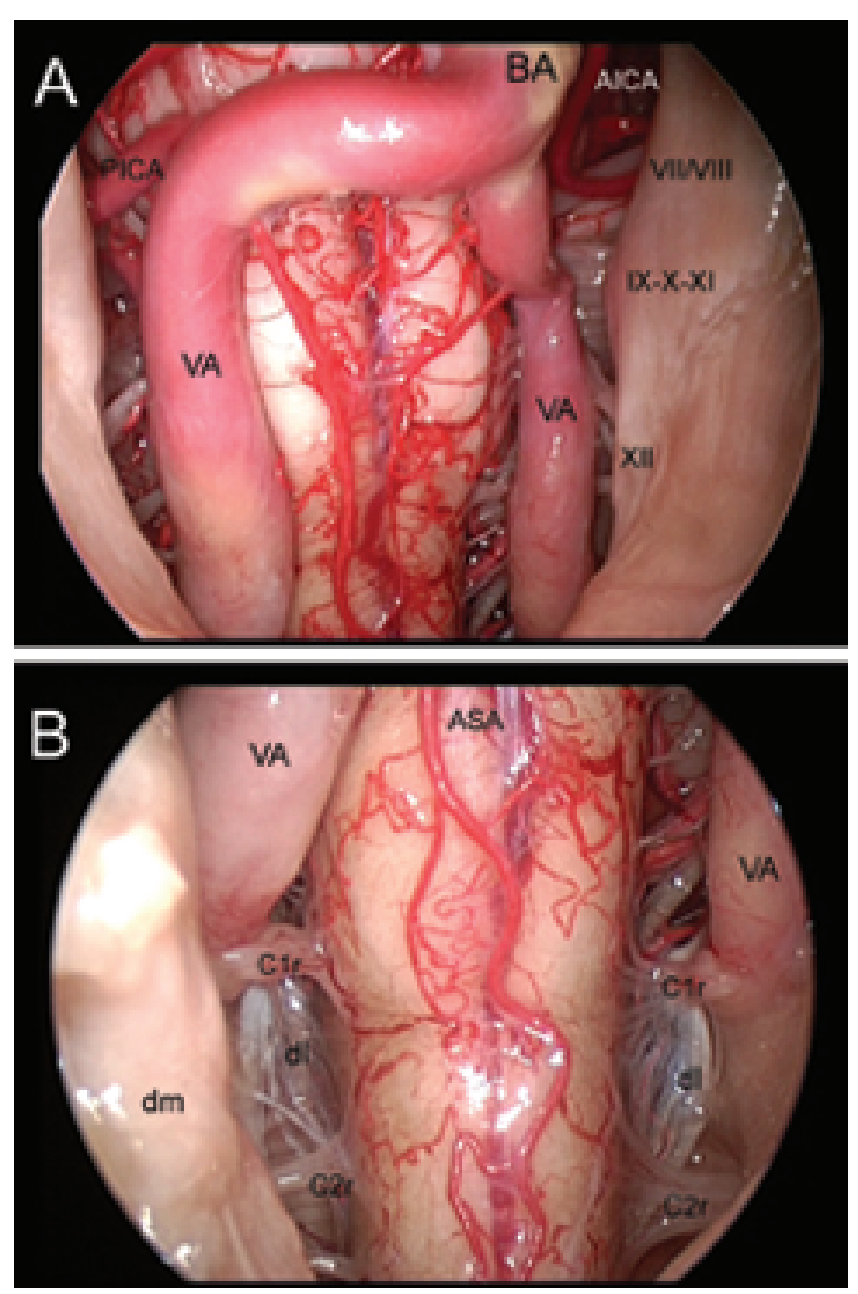

Fig. 22. Endoscopic views obtained in a cadaver, showing the extended approach to the craniovertebral junction and anterior portion of the foramen magnum (intradural step). A: The dura mater has been opened and laterally reflected. The VAs, the spinomedullary junction, and the lower cranial nerves are exposed. $\mathrm{B}$ : Angling the scope caudally, the entrance of the VAs into the vertebral canal as well as the ventral rootlets of the first two cervical nerves and the dentate ligaments is visible. ASA = anterior spinal artery; $\mathrm{C} 1 \mathrm{r}=$ ventral rootlets of the first cervical nerve; $\mathrm{C} 2 \mathrm{r}=$ ventral rootlets of the second cervical nerve; $\mathrm{dl}=$ dentate ligament; IX-X-XI = glossopharyngeal, vagus, and accessory (ninth-11th cranial) nerves; PICA = posterior inferior cerebellar artery; VII/VIII = acoustic-facial nerve bundle; XII = hypoglossal $(12$ th cranial) nerve.

The potential complications or difficulties associated with the extended endonasal approach to the midline skull base are as follows. First, increased bleeding from circular sinuses, either superior or inferior, or from the venous plexuses on the dura mater covering the clivus; this bleeding may become difficult to control with bipolar cauterization when these areas are approached via the endonasal route, which has a narrower, limited working space when compared with some open approaches; different techniques may be required to achieve adequate hemostasis. Second, this approach has higher rates of postoperative CSF leak-
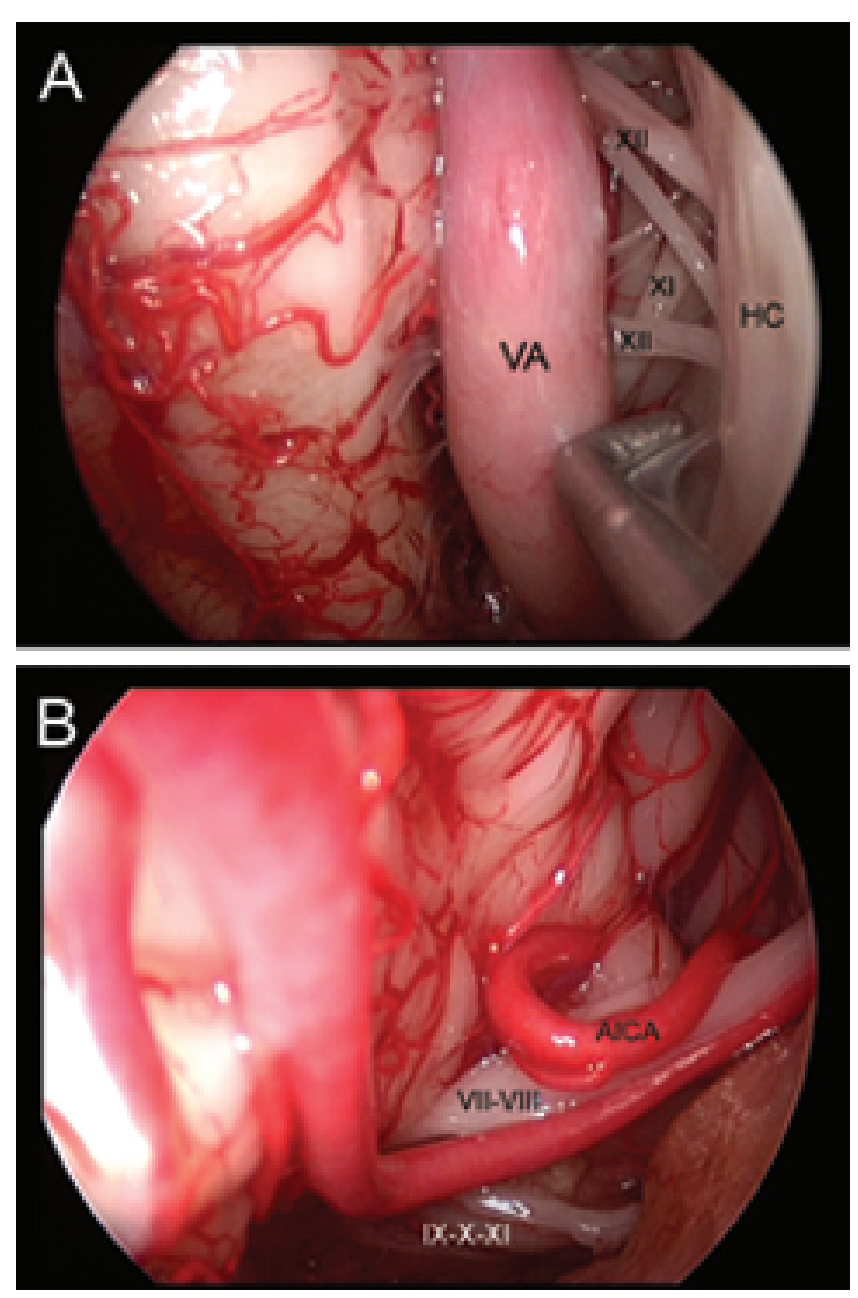

Fig. 23. Endoscopic views obtained in a cadaver, showing the extended approach to the craniovertebral junction and anterior portion of the foramen magnum (intradural step). A: The left VA has been medialized for better visualization of the hypoglossal rootlets exiting through the hypoglossal canal. Note that behind the hypoglossal nerve lies the spinal rootlet of the accessory nerve. B: Passing with the endoscope above the left VA, the lower cranial nerves and the acoustic-facial nerve bundle are exposed. $\mathrm{HC}=$ hypoglossal canal; XI = spinal rootlet of the accessory nerve; $\mathrm{XII}=$ hypoglossal rootlets

age, which is the most common complication related to extended transsphenoidal surgical approaches, with rates ranging from 1.5 to $6.4 \%$. Further complicating this task is the very large CSF space created as a result of lesion removal. Repair of such large defects may be accomplished by the following methods: 1) placing either autologous or allogeneic tissue that spans the defect and effectively creates a watertight seal; 2) creating an effective buttress to hold the implanted tissue in place; and 3) use of temporary decompression of the repair with 48 to 72 hours of CSF diversion.

With the endoscopic endonasal approach, dedicated instruments are needed. A high-speed, low-profile, extendable drill, surgical Doppler ultrasonography, endonasal bipolar forceps, surgical image guidance systems, low-profile ultrasonic aspirator, and endonasal microinstruments are all 


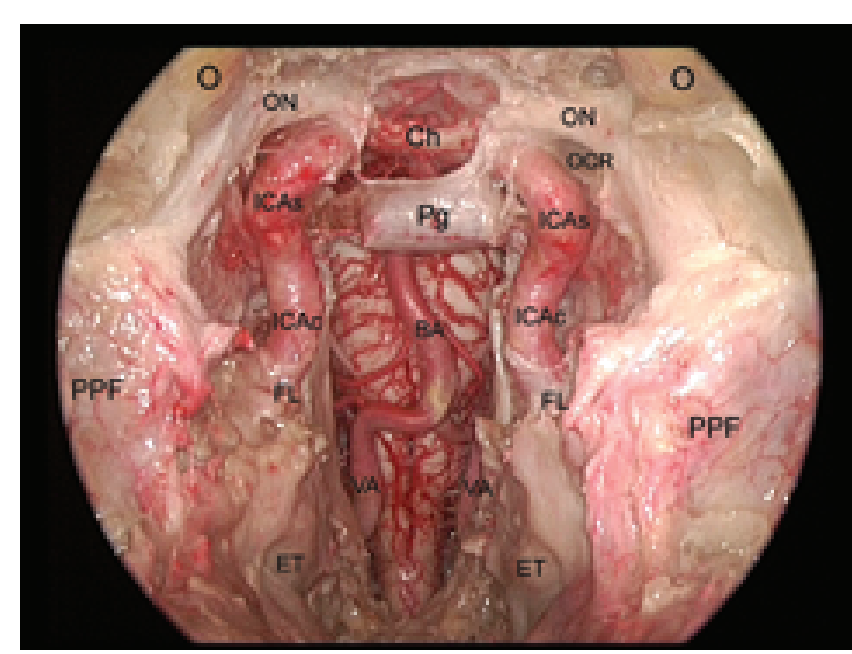

Fig. 24. Panoramic endoscopic view obtained at the end of the dissection. The midline skull base from the planum sphenoidale to the craniovertebral junction is visible in the same image. PPF = pterygopalatine fossa.

potentially beneficial, if not necessary, to perform surgery in these areas in the safest and most effective possible manner.

\section{CONCLUSIONS}

This anatomical study was performed to demonstrate the feasibility of the endoscopic endonasal approach to the midline skull base. With this approach it is possible to expose the intradural cranial base, from the olfactory groove to the odontoid process of C-2. For clinical applications of this approach, the most common surgery-related problems are related to the prevention of postoperative CSF leakage and, in cases involving the lower skull base, the usual issues of stability of the craniovertebral junction. Nevertheless, the potential benefits of such an approach, which allows exposure of the surgical area with no skin incision or neurovascular retraction, cannot be overestimated.

Obviously, these approaches should be performed only by experienced neurosurgeons with adequate endoscopic skill, which can be obtained after dissection studies in cadavers and completion of many endoscopic endonasal surgeries, with the close cooperation and collaboration of ear, nose, and throat surgeons.

\section{References}

1. Alfieri A, Jho HD, Schettino R, et al: Endoscopic endonasal approach to the pterygopalatine fossa: anatomic study. Neurosurgery 52:374-380, 2003

2. Alfieri A, Jho HD, Tschabitscher M: Endoscopic endonasal approach to the ventral cranio-cervical junction: anatomical study. Acta Neurochir 144:219-22, 2002

3. al-Mefty O, Ayoubi S, Smith RR: The petrosal approach: indications, technique, and results. Acta Neurochir Suppl 53: 166-170, 1991

4. Cappabianca P, Cavallo LM, de Divitiis E: Endoscopic endonasal transsphenoidal surgery. Neurosurgery 55:933-941, 2004

5. Cappabianca P, de Divitiis O, Maiuri F: Evolution of transsphenoidal surgery, in de Divitiis E, Cappabianca P (eds): Endoscopic Endonasal Transsphenoidal Surgery. New York: Springer, 2003, pp 1-7
6. Cavallo LM, Cappabianca P, Galzio R, et al: Endoscopic transnasal approach to the cavernous sinus versus transcranial route: anatomical study. Neurosurgery 56 (Suppl 2):379-389, 2005

7. Chanda A, Nanda A: Partial labyrinthectomy petrous apicectomy approach to the petroclival region: an anatomic and technical study. Neurosurgery 51:147-160, 2002

8. Cho CW, al-Mefty O: Combined petrosal approach to petroclival meningiomas. Neurosurgery 51:708-718, 2002

9. Cohan P, Foulad A, Esposito F, et al: Symptomatic Rathke's cleft cysts: a report of 24 cases. J Endocrinol Invest 27:943-948, 2004

10. Cook S, Smith Z, Kelly DF: Endonasal transsphenoidal removal of tuberculum sellae meningiomas: technical note. Neurosurgery 55:239-246, 2004

11. Couldwell WT, Weiss MH, Rabb C, et al: Variations on the standard transsphenoidal approach to the sellar region, with emphasis on the extended approaches and parasellar approaches: surgical experience in 105 cases. Neurosurgery 55:539-550, 2004

12. Crumley RL, Gutin PH: Surgical access for clivus chordoma. The University of California, San Francisco, experience. Arch Otolaryngol Head Neck Surg 115:295-300, 1989

13. de Divitiis E, Cappabianca P, Cavallo LM: Endoscopic transsphenoidal approach: adaptability of the procedure to different sellar lesions. Neurosurgery 51:699-707, 2002

14. de Divitiis O, Conti A, Angileri FF, et al: Endoscopic transoraltransclival approach to the brainstem and surrounding cisternal space: anatomic study. Neurosurgery 54:125-130, 2004

15. Donald PJ (ed): Surgery of the Skull Base. Philadelphia: Lippincott-Raven Publishers, 1998, pp 507-532

16. Dusick JR, Esposito F, Kelly DF, et al: The extended direct endonasal transsphenoidal approach for nonadenomatous suprasellar tumors. J Neurosurg 102:832-841, 2005

17. Esposito F, Becker DP, Villablanca JP, et al: Endonasal transsphenoidal transclival removal of prepontine epidermoid tumors: technical note. Neurosurgery 56 (Suppl 2):E443, 2005

18. Fahlbusch R, Schott W: Pterional surgery of meningiomas of the tuberculum sellae and planum sphenoidale: surgical results with special consideration of ophthalmological and endocrinological outcomes. J Neurosurg 96:235-243, 2002

19. Frank G, Pasquini E, Mazzatenta D: Extended transsphenoidal approach. J Neurosurg 95:917-918, 2001

20. Goel A, Desai K, Muzumdar D: Surgery on anterior foramen magnum meningiomas using a conventional posterior suboccipital approach: a report on an experience with 17 cases. Neurosurgery 49:102-107, 2001

21. Goel A, Muzumdar D, Desai KI: Tuberculum sellae meningioma: a report on management on the basis of a surgical experience with 70 patients. Neurosurgery 51:1358-1364, 2002

22. Grisoli F, Diaz-Vasquez P, Riss M, et al: Microsurgical management of tuberculum sellae meningiomas. Results in 28 consecutive cases. Surg Neurol 26:37-44, 1986

23. Hakuba A, Liu S, Nishimura S: The orbitozygomatic infratemporal approach: a new surgical technique. Surg Neurol 26: 271-276, 1986

24. Hakuba A, Nishimura S, Jang BJ: A combined retroauricular and preauricular transpetrosal-transtentorial approach to clivus meningiomas. Surg Neurol 30:108-116, 1988

25. Honegger J, Fahlbusch R, Buchfelder M, et al: The role of transsphenoidal microsurgery in the management of sellar and parasellar meningioma. Surg Neurol 39:18-24, 1993

26. Jallo GI, Benjamin V: Tuberculum sellae meningiomas: microsurgical anatomy and surgical technique. Neurosurgery 51: 1432-1440, 2002

27. James D, Crockard HA: Surgical access to the base of skull and upper cervical spine by extended maxillotomy. Neurosurgery 29:411-416, 1991

28. Javed T, Sekhar LN: Surgical management of clival meningiomas. Acta Neurochir Suppl 53:171-182, 1991 
29. Jho HD: Endoscopic endonasal skull base surgery for midline lesions from olfactory groove to distal clivus, in 67th Annual Meeting of the American Association of Neurological Surgeons, New Orleans, Louisiana, 1999. Park Ridge, IL: American Association of Neurological Surgeons

30. Jho HD, Alfieri A: Endoscopic glabellar approach to the anterior skull base: a technical note. Minim Invasive Neurosurg 45: 185-188, 2002

31. Jho HD, Ha HG: Endoscopic endonasal skull base surgery: part 1-the midline anterior fossa skull base. Minim Invasive Neurosurg 47:1-8, 2004

32. Jho HD, Ha HG: Endoscopic endonasal skull base surgery: part 2-the cavernous sinus. Minim Invasive Neurosurg 47:9-15, 2004

33. Jho HD, Ha HG: Endoscopic endonasal skull base surgery: part 3-the clivus and posterior fossa. Minim Invasive Neurosurg 47:16-23, 2004

34. Kaptain GJ, Vincent DA, Sheehan JP, et al: Transsphenoidal approaches for the extracapsular resection of midline suprasellar and anterior cranial base lesions. Neurosurgery 49:94-101, 2001

35. Kato T, Sawamura Y, Abe H, et al: Transsphenoidal-transtuberculum sellae approach for supradiaphragmatic tumors: technical note. Acta Neurochir 140:715-719, 1998

36. Kawase T, Shiobara R, Toya S: Anterior transpetrosal-transtentorial approach for sphenopetroclival meningiomas: surgical method and results in 10 patients. Neurosurgery 28:869-876, 1991

37. Kim J, Choe I, Bak K, et al: Transsphenoidal supradiaphragmatic intradural approach: technical note. Minim Invasive Neurosurg 43:33-37, 2000

38. Kitano M, Taneda M: Extended transsphenoidal approach with submucosal posterior ethmoidectomy for parasellar tumors. Technical note. J Neurosurg 94:999-1004, 2001

39. Kobayashi S, Takemae T, Sugita K: [Combined transsphenoidal and transoral approach for clivus chordoma.] No Shinkei Geka 12:1339-1346, 1984 (Jpn)

40. Kouri JG, Chen MY, Watson JC, et al: Resection of suprasellar tumors by using a modified transsphenoidal approach. Report of four cases. J Neurosurg 92:1028-1035, 2000

41. Lakhdar A, Sami A, Naja A, et al: Kyste epidermoide de l'angle ponto-cérébelleux Neurochirurgie 49:13-24, 2003

42. Lalwani AK, Kaplan MJ, Gutin PH: The transsphenoethmoid approach to the sphenoid sinus and clivus. Neurosurgery 31: 1008-1014, 1992

43. Lang DA, Neil-Dwyer G, Iannotti F: The suboccipital transcondylar approach to the clivus and cranio-cervical junction for ventrally placed pathology at and above the foramen magnum. Acta Neurochir 125:132-137, 1993

44. Lang J: Clincal Anatomy of the Posterior Cranial Fossa and Its Foramina. New York: Thieme, 1991, pp 1-112

45. Laws ER: Clivus chordomas, in Sekhar LN, Janecka IP (eds): Surgery of Cranial Base Tumors. New York: Raven Press, 1993, pp 679-685

46. Laws ER Jr: Transsphenoidal surgery for tumors of the clivus. Otolaryngol Head Neck Surg 92:100-101, 1984

47. Liu JK, Das K, Weiss MH, et al: The history and evolution of transsphenoidal surgery. J Neurosurg 95:1083-1096, 2001

48. Liu JK, Decker D, Schaefer SD, et al: Zones of approach for craniofacial resection: minimizing facial incisions for resection of anterior cranial base and paranasal sinus tumors. Neurosurgery 53:1126-1137, 2003

49. MacDonald JD, Antonelli P, Day AL: The anterior subtemporal, medial transpetrosal approach to the upper basilar artery and ponto-mesencephalic junction. Neurosurgery 43:84-89, 1998

50. Maira G, Pallini R, Anile C, et al: Surgical treatment of clival chordomas: the transsphenoidal approach revisited. J Neurosurg 85:784-792, 1996

51. McDonald TJ, Laws ER Jr: Historical aspects of the management of pituitary disorders with emphasis on transsphenoidal surgery, in Laws ER Jr, Randall RV, Kern EB, et al (eds): Management of Pituitary Adenomas and Related Lesions With Emphasis on Transsphenoidal Microsurgery. New York: Appleton-Century-Crofts, 1982, pp 1-13

52. Miller E, Crockard HA: Transoral transclival removal of anteriorly placed meningiomas at the foramen magnum. Neurosurgery 20:966-968, 1987

53. Nakamura M, Samii M: Surgical management of a meningioma in the retrosellar region. Acta Neurochir 145:215-220, 2003

54. Puxeddu R, Lui MW, Chandrasekar K, et al: Endoscopic-assisted transcolumellar approach to the clivus: an anatomical study. Laryngoscope 112:1072-1078, 2002

55. Rabadan A, Conesa H: Transmaxillary-transnasal approach to the anterior clivus: a microsurgical anatomical model. Neurosurgery 30:473-482, 1992

56. Reisch R, Bettag M, Perneczky A: Transoral transclival removal of anteriorly placed cavernous malformations of the brainstem. Surg Neurol 56:106-116, 2001

57. Rhoton AL Jr: The supratentorial cranial space: microsurgical anatomy. Neurosurgery 51 (Suppl 1):S1-273-S1-302, 2002

58. Romano A, Zuccarello M, van Loveren HR, et al: Expanding the boundaries of the transsphenoidal approach: a microanatomic study. Clin Anat 14:1-9, 2001

59. Samii M, Ammirati M: The combined supra-infratentorial presigmoid sinus avenue to the petro-clival region. Surgical technique and clinical applications. Acta Neurochir 95:6-12, 1988

60. Sano K: Temporo-polar approach to aneurysms of the basilar artery at and around the distal bifurcation: technical note. Neurol Res 2:361-367, 1980

61. Seifert V, Raabe A, Zimmermann M: Conservative (labyrinthpreserving) transpetrosal approach to the clivus and petroclival region-indications, complications, results and lessons learned. Acta Neurochir 145:631-642, 2003

62. Sepehrnia A, Knopp U: The combined subtemporal-suboccipital approach: a modified surgical access to the clivus and petrous apex. Minim Invasive Neurosurg 45:102-104, 2002

63. Spencer WR, Levine JM, Couldwell WT, et al: Approaches to the sellar and parasellar region: a retrospective comparison of the endonasal-transsphenoidal and sublabial-transsphenoidal approaches. Otolaryngol Head Neck Surg 122:367-369, 2000

64. Talacchi A, Sala F, Alessandrini F, et al: Assessment and surgical management of posterior fossa epidermoid tumors: report of 28 cases. Neurosurgery 42:242-252, 1998

65. Weiss MH: Transnasal transsphenoidal approach, in Apuzzo MLJ (ed): Surgery of the Third Ventricle. Baltimore: Williams \& Wilkins, 1987, pp 476-494

66. Zada G, Kelly DF, Cohan P, et al: Endonasal transsphenoidal approach for pituitary adenomas and other sellar lesions: an assessment of efficacy, safety, and patient impressions. J Neurosurg 98:350-358, 2003

Manuscript received May 19, 2005.

Accepted in final form June 16, 2005.

Address reprint requests to: Paolo Cappabianca, M.D., Department of Neurological Sciences, Division of Neurosurgery, Università degli Studi di Napoli Federico II, Via S. Pansini, 5, 80131 Naples, Italy. email: paolo.cappabianca@unina.it. 